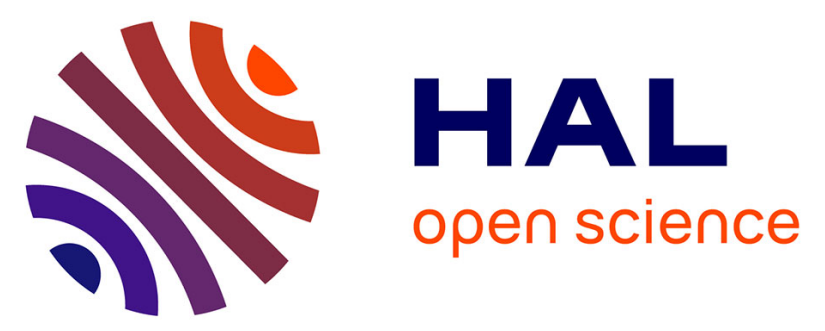

\title{
Cardiac arrhythmia mechanisms in rats with heart failure induced by pulmonary hypertension
}

\author{
David Benoist, Rachel Stones, Mark J Drinkhill, Alan P Benson, Zhaokang \\ Yang, Cécile Cassan, Stephen Gilbert, David A Saint, Olivier Cazorla, Derek \\ D. Steele, et al.
}

\section{To cite this version:}

David Benoist, Rachel Stones, Mark J Drinkhill, Alan P Benson, Zhaokang Yang, et al.. Cardiac arrhythmia mechanisms in rats with heart failure induced by pulmonary hypertension. AJP - Heart and Circulatory Physiology, 2012, 302 (11), pp.H2381 - H2395. 10.1152/ajpheart.01084.2011 . hal01824331

\section{HAL Id: hal-01824331 \\ https://hal.umontpellier.fr/hal-01824331}

Submitted on 13 Apr 2020

HAL is a multi-disciplinary open access archive for the deposit and dissemination of scientific research documents, whether they are published or not. The documents may come from teaching and research institutions in France or abroad, or from public or private research centers.
L'archive ouverte pluridisciplinaire HAL, est destinée au dépôt et à la diffusion de documents scientifiques de niveau recherche, publiés ou non, émanant des établissements d'enseignement et de recherche français ou étrangers, des laboratoires publics ou privés. 


\title{
Cardiac arrhythmia mechanisms in rats with heart failure induced by pulmonary hypertension
}

\author{
David Benoist, ${ }^{1,3,4}$ Rachel Stones, ${ }^{1,3}$ Mark J. Drinkhill, ${ }^{2,3}$ Alan P. Benson, ${ }^{1,3}$ Zhaokang Yang,,3 \\ Cecile Cassan, ${ }^{5}$ Stephen H. Gilbert, ${ }^{1,3,4}$ David A. Saint, ${ }^{6}$ Olivier Cazorla, ${ }^{5}$ Derek S. Steele, ${ }^{1,3}$ \\ Olivier Bernus, ${ }^{1,3,4}$ and Ed White ${ }^{1,3}$ \\ ${ }^{1}$ Institute of Membrane and Systems Biology, ${ }^{2}$ Division of Cardiovascular and Neuronal Remodelling, and ${ }^{3}$ Multidisciplinary \\ Cardiovascular Research Centre, University of Leeds, Leeds, United Kingdom; ${ }^{4}$ U-1045, Institut National de la Santé et de la \\ Recherche Médicale (INSERM), Centre de Recherche Cardio-Thoracique, Université Bordeaux Segalen, Bordeaux; \\ ${ }^{5}$ U-1046, INSERM, Université Montpellier 1 and 2, Montpellier, France; and ${ }^{6}$ School of Medical Sciences, University of \\ Adelaide, Adelaide, South Australia, Australia
}

Benoist D, Stones R, Drinkhill MJ, Benson AP, Yang Z, Cassan C, Gilbert SH, Saint DA, Cazorla O, Steele DS, Bernus O, White E. Cardiac arrhythmia mechanisms in rats with heart failure induced by pulmonary hypertension.

-Pulmonary hypertension provokes right heart failure and arrhythmias. Better understanding of the mechanisms underlying these arrhythmias is needed to facilitate new therapeutic approaches for the hypertensive, failing right ventricle (RV). The aim of our study was to identify the mechanisms generating arrhythmias in a model of RV failure induced by pulmonary hypertension. Rats were injected with monocrotaline to induce either RV hypertrophy or failure or with saline (control). ECGs were measured in conscious, unrestrained animals by telemetry. In isolated hearts, electrical activity was measured by optical mapping and myofiber orientation by diffusion tensor-MRI. Sarcoplasmic reticular $\mathrm{Ca}^{2+}$ handling was studied in single myocytes. Compared with control animals, the T-wave of the ECG was prolonged and in three of seven heart failure animals, prominent $\mathrm{T}$-wave alternans occurred. Discordant action potential (AP) alternans occurred in isolated failing hearts and $\mathrm{Ca}^{2+}$ transient alternans in failing myocytes. In failing hearts, AP duration and dispersion were increased; conduction velocity and AP restitution were steeper. The latter was intrinsic to failing single myocytes. Failing hearts had greater fiber angle disarray; this correlated with AP duration. Failing myocytes had reduced sarco(endo)plasmic reticular $\mathrm{Ca}^{2+}$-ATPase activity, increased sarcoplasmic reticular $\mathrm{Ca}^{2+}$-release fraction, and increased $\mathrm{Ca}^{2+}$ spark leak. In hypertrophied hearts and myocytes, dysfunctional adaptation had begun, but alternans did not develop. We conclude that increased electrical and structural heterogeneity and dysfunctional sarcoplasmic reticular $\mathrm{Ca}^{2+}$ handling increased the probability of alternans, a proarrhythmic predictor of sudden cardiac death. These mechanisms are potential therapeutic targets for the correction of arrhythmias in hypertensive, failing RVs.

electrocardiography; monocrotaline; calcium signaling; voltage-sensitive dye imaging; alternans

ALTHOUGH RIGHT VENTRICULAR (RV) failure most often develops as a consequence of left ventricular (LV) failure, RV failure occurs in many, increasingly common, diseases associated with dysfunction of the pulmonary circulation $(6,18,58)$. This includes pulmonary hypertension, where RV failure is the

Address for reprint requests and other correspondence: E. White, Institute of Membrane and Systems Biology, Garstang Bld., Univ. of Leeds, Leeds LS29JT, UK (e-mail: e.white@leeds.ac.uk). major cause of death in patients (6). Pulmonary hypertension is associated with RV electrical remodeling $(23,26,27)$ and a higher risk of arrhythmias (17). Sudden death occurs in 30$40 \%$ of sufferers $(10,63)$, and lethal arrhythmias are thought to be one cause, in addition to other mechanisms, such as pulmonary embolism and pulmonary artery dissection. Interestingly, the RV is not currently a target for therapeutic intervention in this disease (19).

There are several established mechanisms by which arrhythmias can arise. Increased electrical heterogeneity and steeper electrical restitution $(1,32,53)$ increase the probability of alternans and arrhythmias. This is because heterogeneity increases the dispersion of refractoriness and steeper restitution decreases the stability of action potential (AP) duration (APD) and diastolic interval adaptation to a change in heart rate, also increasing the dispersion of refractoriness. This makes conduction block and reentry more likely $(9,35,49,60)$. Alternans describe the events where parameters such as APD or intracellular $\mathrm{Ca}^{2+}$ concentration $\left(\left[\mathrm{Ca}^{2+}\right]_{\mathrm{i}}\right)$ transient amplitude alternate in size on a beat-to-beat basis. They are established predictors of sudden cardiac death, and discordant alternans, where the parameter in question is out of phase in different regions of the ventricles, are most likely to generate reentrant arrhythmias $(9,35,49,60)$.

Defective $\mathrm{Ca}^{2+}$ handling also leads to the generation of arrhythmias. Increased sarcoplasmic reticulum (SR) $\mathrm{Ca}^{2+}$ leak, $\mathrm{SR}$ release fraction, $\mathrm{SR} \mathrm{Ca}^{2+}$ content, and slowed $\mathrm{SR} \mathrm{Ca}^{2+}$ reuptake are thought to contribute to the generation of $\mathrm{Ca}^{2+}$ transient alternans and thus to APD and T-wave alternans (via modulation of $\mathrm{Ca}^{2+}$-dependent currents) by facilitating beatto-beat fluctuations in $\mathrm{SR} \mathrm{Ca}^{2+}$ release $(38,49)$. This is because increased SR $\mathrm{Ca}^{2+}$ content favors SR $\mathrm{Ca}^{2+}$ leak and places activated ryanodine receptors in a refractory state for the next beat, leading to fluctuations in $\mathrm{SR} \mathrm{Ca}^{2+}$ release (48). Additionally, elevated $\mathrm{SR} \mathrm{Ca}^{2+}$ content and release fraction in the presence of a slowed $\mathrm{SR} \mathrm{Ca}^{2+}$ reuptake lead to intra-SR fluctuations in $\mathrm{Ca}^{2+}$ content (13).

Structural changes, such as an alteration in connexin expression or increased fibrosis, which disrupts the normal myofiber organization, can slow conduction, create electrical heterogeneity (31), and contribute to dysfunctional electrical activity (16). Given the number of potential arrhythmic mechanisms, the specific occurrence and relative importance of these mechanisms need to be characterized for any given pathology, if that pathology is to be fully understood and treated. 
We have reported a proarrhythmic state in a model of RV failure induced by pulmonary hypertension where changes in ion channel gene expression and monophasic APD are predominantly found in the RV compared with the LV (3). The purpose of this study was to investigate changes in RV electrophysiology and structure, at two stages of the disease, to identify the mechanisms responsible for the proarrhythmic state.

\section{METHODS}

Experiments were approved by the local ethical committee and the United Kingdom Home Office. Male Wistar rats (200 g) received a single intraperitoneal injection of monocrotaline (MCT) to induce stable RV hypertrophy (HYP; $30 \mathrm{mg} / \mathrm{kg}$ in saline, $N=11$ ) or RV failure (FAIL; $60 \mathrm{mg} / \mathrm{kg}$ in saline, $N=34$ ) or were injected with an equivalent volume of saline [control $(\mathrm{CON}) ; N=32$ ]. Animals were weighed weekly for $3 \mathrm{wk}$ postinjection and then daily. Ethical approval required that FAIL animals were killed upon displaying clinical signs of heart failure, e.g., dyspnea, cold extremities, lethargy, or any weight loss on consecutive days. CON and HYP animals were killed on equivalent days postinjection.

Echocardiography. Doppler echocardiography was performed in anesthetized but spontaneously breathing animals (2\% isoflurane, Baxter) with a Vivid7Pro (GE Healthcare) equipped with a $10-\mathrm{MHz}$ transducer. Rats were positioned on their left side. A two-dimensional view of both the LV and RV was obtained at the level of the papillary muscles in a parasternal short-axis view (50). LV morphological parameters were measured from M-mode traces recorded through the anterior and posterior walls (11). LV fractional shortening (FS) was calculated as follows: LVFS $=$ [(LVIDd - LVIDs $) /$ LVIDd $\times 100]$, where LVIDd and LVIDs are the end-diastolic and end-systolic LV internal dimensions, respectively.

$\mathrm{RV}$ wall thickness was assessed in two-dimensional parasternal short-axis view in diastole. RV end-diastolic diameter was measured as the maximal distance from the RV free wall to the septum in a four-chamber view. RVFS was calculated as follows: RVSF = [(RVAd - RVAs $) / R V A d \times 100]$, where RVAd and RVAs are the RV areas in diastole and systole, respectively, measured in the fourchamber view. The RV maximal value of $\mathrm{E}$ wave velocity was measured by Doppler in the four-chamber view. Doppler imaging of the pulmonary outflow was recorded in a parasternal view at the level of the aortic valves. Pulmonary artery acceleration time (PAAT) was measured from the onset of systolic flow to the maximum pulmonary outflow velocity and normalized to cardiac cycle length (CL). Decreasing PAAT/CL can be used as a serial noninvasive indicator of increasing pulmonary artery systolic pressure $(20,30)$. The velocity time integral of pulmonary artery flow was measured on the same images. Doppler assessment of the velocity time integral of aortic flow was performed in a suprasternal view, with rats positioned on their back (54).

Telemetric monitoring of ECG. Surgical implantation of telemetry devices (TA10ETA-F20, Data Sciences, St. Paul, MN) was conducted under $2-3 \%$ isoflurane anesthesia using aseptic techniques. Devices designed for mice, which are smaller and lighter than standard rat devices, were used to minimize the impact of implantation. ECGs were recorded in conscious, unrestrained rats. Two-hour sections of data, acquired with Dataquest A.R.T. 4.1 Gold software (Data Sciences) midway through the light cycle of a 12:12-h light-dark lighting regime were analyzed with Ponemah software (P3 Plus version 4.4, Data Sciences). The R-R interval (the inverse of heart rate), duration of the QRS complex (an indicator of ventricular activation time), QT interval (an indicator of ventricular repolarization time), and time from $\mathrm{T}$-wave peak to end $\left(\mathrm{T}_{\mathrm{pe}}\right.$; an indicator of the global dispersion of APD) were measured. ECG traces were also analyzed with Chart 7 (AD Instruments), and a custom-written $\mathrm{C}++$ program was used to detect alternans in T-wave amplitude and QT interval. An alternating $4 \%$ difference in $\mathrm{T}$-wave parameters for at least 10 consecutive beats was counted as an alternans event, and the frequency of these events was recorded. These thresholds were chosen to allow manual verification and to accommodate signal-to-noise levels. Between 13,000 and 22,000 ECG waveforms were analyzed from each heart.

Optical mapping of electrical activity in isolated hearts. Isolated hearts were perfused at $37^{\circ} \mathrm{C}$ with a modified Krebs-Henseleit solution containing (in mmol/l) $130 \mathrm{NaCl}, 24 \mathrm{NaHCO}_{3}, 1.2 \mathrm{NaH}_{2} \mathrm{PO}_{4}, 1$ $\mathrm{MgCl}_{2}, 5.6$ glucose, $4 \mathrm{KCl}$, and $1.8 \mathrm{CaCl}_{2}$ (pH equilibrated to 7.4 with $95 \% \mathrm{O}_{2}-5 \% \mathrm{CO}_{2}$ ). To perform optical mapping of electrical activity $(29,59)$, motion artifacts were prevented using $10 \mathrm{mmol} / \mathrm{l} 2,3-$ butanedione monoxime (BDM) as an electromechanical uncoupler. This solution was recirculated throughout the duration of the experi-
Fig. 1. Echocardiographic images of control (CON) and monocrotaline (MCT)-treated [right ventricular (RV) failing (FAIL)] animals. A: two-dimensional (2-D) parasternal short-axis view in a representative $\mathrm{CON}$ and FAIL animal 22 days after saline or $60 \mathrm{mg} / \mathrm{kg}$ MCT treatment. RV, RV cavity; LV, left ventricular (LV) cavity; IVS, interventricular septum. In FAIL animals, the RV is enlarged and hypertrophic, and the LV morphology is altered. $B$ : pulmonary artery outflow, obtained by Doppler, was decreased in MCT-treated animals. $C$ : M-mode traces of the LV (parasternal short-axis view). Images show evidence of reduced LV diameters and decreased contractility.
Pulmonary artery outflow

\section{D parasternal short axis view}

A

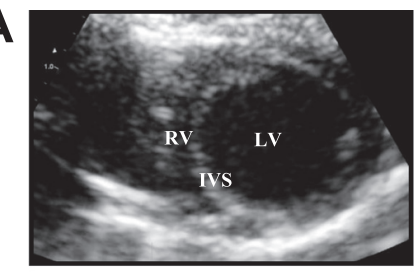

B



C

M-mode traces on LV (parasternal short axis view)
CON

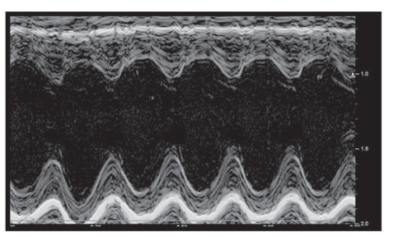

FAIL
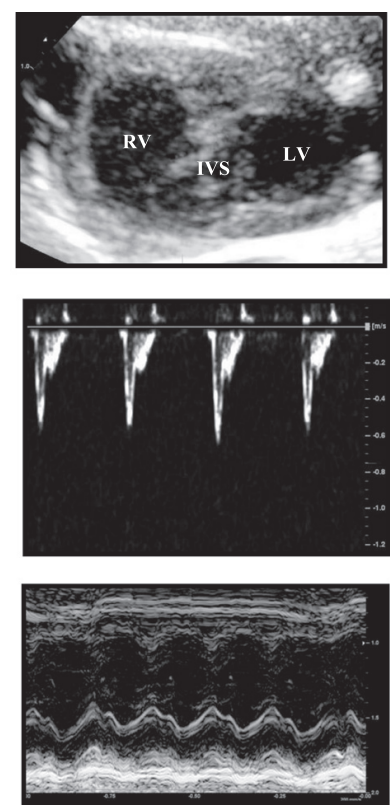
Table 1. Echocardiographic parameters for CON and monocrotaline-treated animals

\begin{tabular}{|c|c|c|c|c|c|c|}
\hline & \multicolumn{2}{|c|}{ Day 0} & \multicolumn{2}{|c|}{ Day 16} & \multicolumn{2}{|c|}{ Day $>21$} \\
\hline & $\mathrm{CON}$ & FAIL & $\mathrm{CON}$ & FAIL & CON & FAIL \\
\hline Body weight, $\mathrm{g}$ & $226 \pm 4$ & $219 \pm 3$ & $325 \pm 3$ & $299 \pm 7 \dagger$ & $353 \pm 5$ & $303 \pm 6 \neq$ \\
\hline Heart rate, beats/min & $408 \pm 6$ & $414 \pm 7$ & $383 \pm 10$ & $391 \pm 9$ & $376 \pm 13$ & $318 \pm 10 \dagger$ \\
\hline Cardiac output, $\mathrm{ml} / \mathrm{min}$ & $91.4 \pm 2.1$ & $96.5 \pm 3.8$ & $102.1 \pm 4.9$ & $100.4 \pm 4.4$ & $92.4 \pm 4.0$ & $35.0 \pm 3.3 \ddagger$ \\
\hline \multicolumn{7}{|l|}{ LV } \\
\hline Posterior wall thickness at diastole, $10^{1} \mathrm{~cm}$ & $15 \pm 0$ & $15 \pm 0$ & $15 \pm 0$ & $16 \pm 0$ & $16 \pm 0$ & $18 \pm 1^{*}$ \\
\hline Internal dimension at diastole, $\mathrm{mm}$ & $7.8 \pm 0.2$ & $7.5 \pm 0.1$ & $8.5 \pm 0.2$ & $8.1 \pm 0.2$ & $8.6 \pm 0.2$ & $7.1 \pm 0.1 \%$ \\
\hline Relative wall thickness & $0.35 \pm 0.01$ & $0.37 \pm 0.01$ & $0.34 \pm 0.01$ & $0.36 \pm 0.01$ & $0.34 \pm 0.01$ & $0.43 \pm 0.01 \$$ \\
\hline FS, \% & $52 \pm 1$ & $50 \pm 1$ & $49 \pm 2$ & $50 \pm 2$ & $50 \pm 1$ & $43 \pm 2 *$ \\
\hline Velocity time integral of aortic flow, $\mathrm{mm}$ & $39.9 \pm 0.6$ & $41.9 \pm 1.5$ & $43.4 \pm 2.0$ & $42.8 \pm 1.7$ & $40.8 \pm 1.1$ & $18.6 \pm 1.3 \$$ \\
\hline \multicolumn{7}{|l|}{$\mathrm{RV}$} \\
\hline Wall thickness at diastole, $\mathrm{mm}$ & $0.64 \pm 0.02$ & $0.62 \pm 0.01$ & $0.62 \pm 0.01$ & $0.66 \pm 0.02$ & $0.63 \pm 0.01$ & $1.40 \pm 0.06 \ddagger$ \\
\hline End-diastolic diameter, $\mathrm{cm}$ & $0.48 \pm 0.01$ & $0.48 \pm 0.01$ & $0.50 \pm 0.01$ & $0.52 \pm 0.02$ & $0.52 \pm 0.02$ & $0.76 \pm 0.04 \ddagger$ \\
\hline FS, \% & $29 \pm 3$ & $31 \pm 2$ & $27 \pm 2$ & $23 \pm 1$ & $30 \pm 2$ & $12 \pm 2 \ddagger$ \\
\hline E wave, $\mathrm{m} / \mathrm{s}$ & $0.90 \pm 0.02$ & $0.88 \pm 0.02$ & $0.87 \pm 0.03$ & $0.88 \pm 0.04$ & $0.88 \pm 0.02$ & $0.69 \pm 0.04 \%$ \\
\hline LVFS/RVFS & $2.6 \pm 0.2$ & $2.3 \pm 0.2$ & $2.5 \pm 0.3$ & $2.8 \pm 0.2$ & $2.4 \pm 0.1$ & $5.4 \pm 1.0^{*}$ \\
\hline \multicolumn{7}{|l|}{ Pulmonary artery } \\
\hline $\mathrm{PAAT} / \mathrm{CL}$ & $0.17 \pm 0.01$ & $0.18 \pm 0.01$ & $0.16 \pm 0.00$ & $0.11 \pm 0.01 \dagger$ & $0.15 \pm 0.01$ & $0.07 \pm 0.00 \%$ \\
\hline Velocity time integral, $\mathrm{cm}$ & $5.69 \pm 0.22$ & $5.40 \pm 0.16$ & $6.04 \pm 0.17$ & $4.89 \pm 0.14 \ddagger$ & $6.16 \pm 0.21$ & $2.47 \pm 0.22 \ddagger$ \\
\hline
\end{tabular}

Values are means \pm SE; $N=8$ animals in the control (CON) group and 8 animals in the monocrotaline-treated [failing (FAIL)] group. Shown are parameters in CON and FAIL animals at 0,16 , and $>21$ days posttreatment. LV, left ventricle; FS, fractional shortening; RV, right ventricle; E wave, maximal value of E wave velocity; PAAT/CL, pulmonary artery acceleration time normalized to cardiac cycle length. $* P<0.05 ; \dagger P<0.01 ; \ddagger P<0.001$.

ment. Hearts were stimulated with the pacing electrode placed at the $\mathrm{RV}$ epicardial surface in the posterior interventricular region. Hearts were then loaded with a $5-\mu \mathrm{g} / \mathrm{ml}$ bolus $(1 \mathrm{ml})$ of di-4-ANEPPS (Biotium) dissolved in DMSO. The dye was excited at $530 \mathrm{~nm}$ using monochromatic light-emitting devices. The emission light was separated with a $700 \pm 50$-nm filter. Excitation light and emission filter wavelengths were selected to provide the optimal voltage-sensitive fluorescent signal. The fluorescent signal was acquired with a $0.25-\mathrm{mm}$ spatial resolution at $1 \mathrm{kHz}$ through a charge-coupled device camera (SciMeasure Analytical Systems) mounted with a lens (focal length: $12 \mathrm{~mm}$, aperture ratio: 1:0.8, Computar). The RV was orientated so that it faced the excitation light source and the camera.

An epicardial mid-RV free wall region of $2.5 \times 2.5 \mathrm{~mm}$ was used for constructing dynamic AP and conduction velocity $(\mathrm{CV})$ restitution curves. APs recorded over a 5-s sequence underwent ensemble averaging followed by temporal $(1.5 \mathrm{~ms}$ kernel) and spatial $(1.0 \mathrm{~mm}$ kernel) filtering. Parameters analyzed included APD at $80 \%$ repolarization $\left(\mathrm{APD}_{80}\right)$ and $\mathrm{CV}$, which was obtained from the activation time across the sampled section of the ventricular free wall. Dynamic restitution characteristics were assessed by increasing stimulation frequency and measuring parameters at each steady state. APD dispersion was calculated as the difference between the maximum and minimum $\mathrm{APD}_{80}$ over the whole imaged portion of the RV surface in each heart. The threshold criterion for APD and AP amplitude alternans was a beat-to-beat difference of $>2$ SD of the mean measured parameter.

Diffusion tensor-MRI. After the optical mapping experiments, some hearts were preserved by perfusion with $4 \%$ formalin. Fixed hearts were immersed in the perfluoropolyether fomblin. Diffusion tensor (DT)-MRI imaging was performed with a NMR spectrometer with a 9.4-T magnet. The spectrometer had an imaging and diffusion probe head to enable DTs to be measured at each voxel within a tissue, the eigenvectors of which quantified the fiber orientation and sheet structure throughout the tissue. High-resolution (200 $\mu \mathrm{m}$ isotropic) imaging of the orthotropic fiber and sheet structure was performed with a reasonably short scan time of $\sim 8 \mathrm{~h}$. Diffusion of protons was measured throughout the tissue in a set of 12 optimized directions (45) using a three-dimensional diffusion-weighted spin-echo sequence with reduced encoding at $20^{\circ} \mathrm{C}$ (repetition time: $500 \mathrm{~ms}$, echo time: 15 $\mathrm{ms}$, diffusion gradients with 2-ms duration and 7-ms separation, $b=$ $\left.1,000 \mathrm{~s} / \mathrm{mm}^{2}\right)$. DTs, and the eigenvectors of these tensors, were calculated from the diffusion measurements, and tissue structure was quantified from these vectors using in-house software.

Analysis of DT-MRI data sets has been previously described (4). Fiber inclination (helix) angles were extracted from 2-mm-thick and $15^{\circ}$-wide sectors of the equatorial LV and RV free walls. Any papillary muscle data were digitally removed. Wall thickness, range of helix angles, and transmural rate of change of the helix angle were calculated from linear fits. The $R^{2}$ value of the linear fit was used to assess heterogeneity in fiber angle.

Simultaneous measurement of shortening and intracellular $\mathrm{Ca}^{2+}$ in single ventricular myocytes. Single cardiac myocytes were isolated as previously described (40). After perfusion with a collagenase- and protease-containing solution, the RV free wall was dissected and RV myocytes were isolated. Myocytes were stored at $20-23^{\circ} \mathrm{C}$ and used within $10 \mathrm{~h}$

Table 2. Animal and organ characteristics of CON and monocrotaline-treated animals

\begin{tabular}{lccc}
\hline \hline & CON & HYP & FAIL \\
\hline Animals/group & 15 & 12 & 17 \\
Body weight, g & $315 \pm 4$ & $300 \pm 7^{\mathrm{e}}$ & $264 \pm 5^{\mathrm{c}}$ \\
Heart weight, g & $1.30 \pm 0.04$ & $1.60 \pm 0.08^{\mathrm{c}}$ & $1.53 \pm 0.03^{\mathrm{b}}$ \\
Lung weight, g & $1.71 \pm 0.07$ & $2.27 \pm 0.11^{\mathrm{c}}$ & $2.81 \pm 0.16^{\mathrm{c}}$ \\
$\begin{array}{c}\text { Heart weight/body weight, } \\
\text { mg/g }\end{array}$ & $4.14 \pm 0.13$ & $5.37 \pm 0.30^{\mathrm{c}}$ & $5.84 \pm 0.17^{\mathrm{c}}$ \\
$\begin{array}{c}\text { Lung weight/Body weight, } \\
\quad \mathrm{mg} / \mathrm{g}\end{array}$ & $5.42 \pm 0.21$ & $7.62 \pm 0.39^{\mathrm{c}, \mathrm{d}}$ & $10.70 \pm 0.70^{\mathrm{c}}$ \\
$\begin{array}{c}\text { Ventricular weights } \\
\quad \text { Hearts/group }\end{array}$ & 10 & 6 & 11 \\
$\quad$ RV weight, g & $0.26 \pm 0.02$ & $0.44 \pm 0.03^{\mathrm{c}}$ & $0.43 \pm 0.02^{\mathrm{c}}$ \\
$\quad$ LV weight, g & $0.60 \pm 0.02$ & $0.56 \pm 0.03$ & $0.51 \pm 0.02^{\mathrm{a}}$ \\
$\quad$ RV weight/LV weight, \\
$\quad$ mg/mg
\end{tabular}

Values are means \pm SE. Shown are whole animal, organ, and ventricular weights from animals used in optical mapping/diffusion tensor (DT)-MRI experiments and single myocyte experiments from CON, hypertrophied (HYP), and FAIL groups. RV and LV weights are RV and LV free wall weights after an exposure to collagenase from animals used in the single myocytes experiments. ${ }^{\mathrm{a}} P<0.05,{ }^{\mathrm{b}} P<0.01$, and ${ }^{\mathrm{c}} P<0.001$ vs. the CON group; ${ }^{\mathrm{d}} P<0.01$ and ${ }^{\mathrm{e}} P<0.001$, HYP group vs. FAIL group. 
Fig. 2. ECGs in conscious, unrestrained CON and FAIL rats. A: representative ECG traces from a CON and FAIL rat 22 days after treatment. B: R-R interval. $C$ : QRS duration. D: QT interval. $E$ : time from $\mathrm{T}$-wave peak to end $\left(\mathrm{T}_{\mathrm{pe}}\right)$ at 1,15 , and $>21$ days after treatment. Open bars, CON animals; solid bars, FAIL animals. Data are means $\pm \mathrm{SE} ; N=9 \mathrm{CON}$ animals and 9 FAIL animals. $* * P<0.01$ and $* * * P<0.001$ vs. CON. The increased QT interval is consistent with a prolonged action potential (AP) duration (APD) and increased $\mathrm{T}_{\mathrm{pe}}$ with increased global dispersion of APD.
A

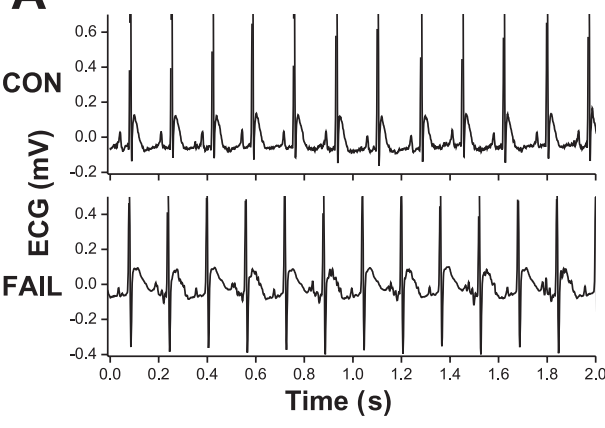

D

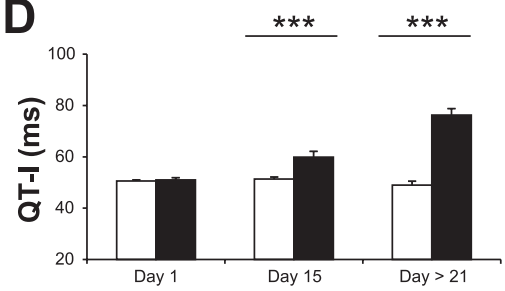

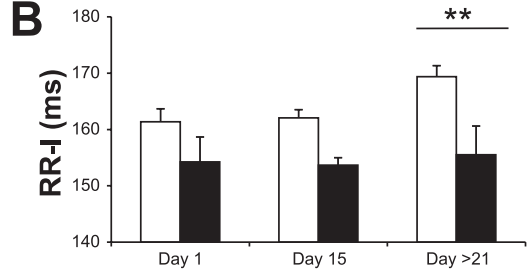

C

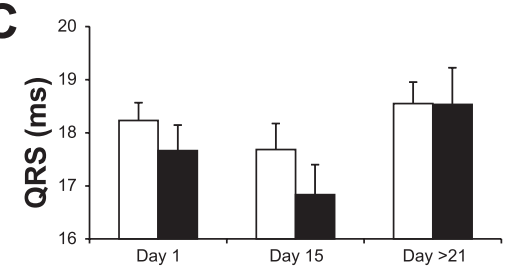

E

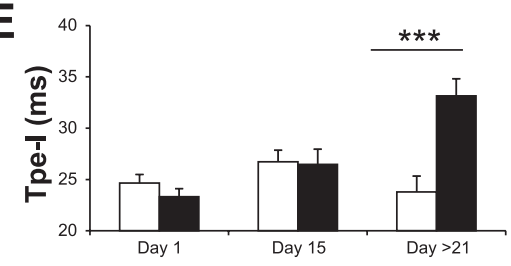

Cells were placed in a chamber on the stage of an inverted microscope (Diaphot, Nikon) and continuously superfused at $\sim 1$ $\mathrm{ml} / \mathrm{min}$ with a HEPES-based Tyrode solution at $37^{\circ} \mathrm{C}$ containing (in mmol/l) $137 \mathrm{NaCl}, 5.4 \mathrm{KCl}, 0.33 \mathrm{NaH}_{2} \mathrm{PO}_{4}, 0.5 \mathrm{MgCl}_{2} \cdot 6 \mathrm{H}_{2} \mathrm{O}, 5$ HEPES, 5.6 glucose, and $1 \mathrm{CaCl}_{2}$ (pH adjusted to 7.4 with $\mathrm{NaOH}$ ). Cells were field stimulated via platinum bath electrodes using a 5-ms pulse at stimulation frequencies between 1 and $9 \mathrm{~Hz}$ to investigate $\left[\mathrm{Ca}^{2+}\right]_{\mathrm{i}}$ transients and fractional shortening.

$\left[\mathrm{Ca}^{2+}\right]_{i}$ was monitored using the fluorescent $\mathrm{Ca}^{2+}$ probe fura- 4 AM (Molecular probes) (34). Isolated cells were loaded with fura-4 AM $(2 \mu \mathrm{mol} / \mathrm{l})$ for $20 \mathrm{~min}$ at $20-23^{\circ} \mathrm{C}$, resuspended in Tyrode solution, and then stored for at least 30 min to allow deesterification of the dye. Myocytes were alternately illuminated with excitation light at 340 and $380 \mathrm{~nm}$ using a monochromator spectrophotometer system (Cairn Research). Emitted light at $510 \mathrm{~nm}$ was collected by a photomultiplier, and the ratio of emitted light in response to 340 - and 380-nm illumination (340-to-380-nm ratio) used as an index of $\left[\mathrm{Ca}^{2+}\right]_{\mathrm{i}}$. The $\left[\mathrm{Ca}^{2+}\right]_{\mathrm{i}}$ transient amplitude was the difference between the diastolic and peak systolic 340-to-380-nm ratio. Sarco(endo)plasmic reticular $\mathrm{Ca}^{2+}$-ATPase (SERCA) is the $\mathrm{Ca}^{2+}$ pump responsible for the uptake of $\mathrm{Ca}^{2+}$ into the SR. To assess the activity of SERCA, cells were stimulated to steady state at a frequency of $5 \mathrm{~Hz}$. Stimulation was stopped, and Tyrode solution containing $20 \mathrm{mmol} / \mathrm{l} \mathrm{caf}-$ feine was applied via a rapid solution changer in close proximity to the cell. Caffeine releases $\mathrm{Ca}^{2+}$ from the SR, and the amplitude of the caffeine-induced $\mathrm{Ca}^{2+}$-transient is an index of $\mathrm{SR} \mathrm{Ca}^{2+}$ content. The
Fig. 3. T-wave alternans in conscious, unrestrained FAIL rats. $A$ : expanded section of the ECG recording shown in Fig. 2 from a FAIL rat 22 days after treatment. T-waves alternated between taller and longer (L) and shorter (S) forms. $B$ : successive alternating T-wave amplitudes and QT intervals from another FAIL animal $>21$ days after treatment. $C$ and $D$ : percentages of beats in a $1-\mathrm{h}$ recording period associated with alternans of T-wave amplitude $(C)$ or QT interval $(D)$ in 7 CON animals (O) and 7 FAIL animals $(\bullet)$. Alternans were quantified as at least a $4 \%$ beat-to-beat alternans of magnitude for at least 10 beats. Box plots in $C$ and $D$ show means, SEs, and $25-75 \%$ ranges.

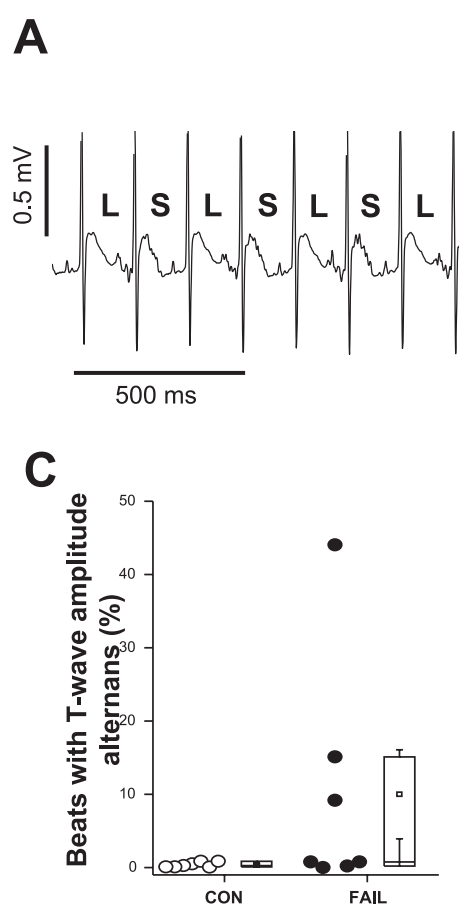

B

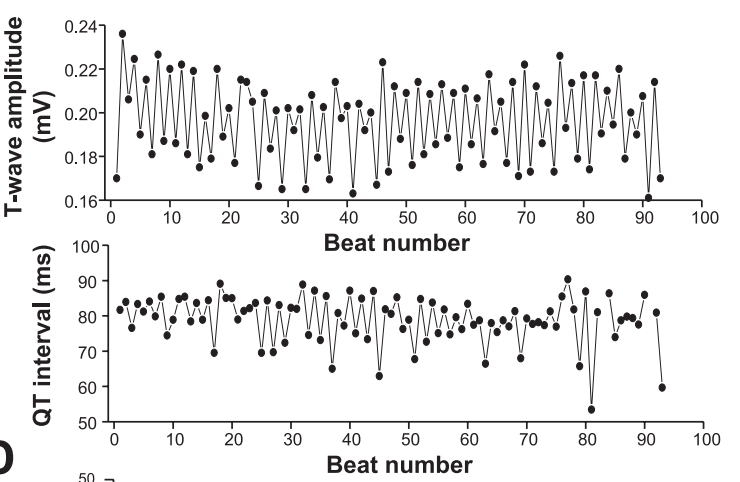

D

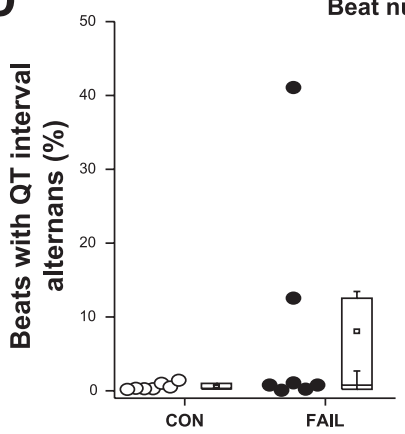


decay of the electrically and caffeine-stimulated $\mathrm{Ca}^{2+}$ transients were fitted to single exponentials, and the difference $\left(K_{\text {SERCA }}\right)$ was used as an index of SERCA activity, because $\mathrm{Ca}^{2+}$ cannot accumulate in the $\mathrm{SR}$ in the presence of caffeine and cytosolic $\mathrm{Ca}^{2+}$ declines principally due to extrusion from the cell via the $\mathrm{Na}^{+} / \mathrm{Ca}^{2+}$ exchanger (see Refs. 12 and 14 for details).

Cell shortening was measured using a video-edge detector (Crescent Electronics) and NTSC TM640 camera (JAI Pulnix) and expressed as a percentage of the diastolic cell length. Cell length and $\left[\mathrm{Ca}^{2+}\right]_{\mathrm{i}}$ were monitored simultaneously in the same cell. Signals were recorded by an Axon Digidata at a sample frequency of $1 \mathrm{kHz}$ and analyzed with pCLAMP 9.2 (Axon Instruments). The threshold criterion for $\mathrm{Ca}^{2+}$ transient alternans was a $5 \%$ beat-to-beat change in amplitude over a 30-beat period.

Measurement of $\mathrm{Ca}^{2+}$ sparks by confocal microscopy. Intact, quiescent myocytes were loaded for $15 \mathrm{~min}$ at $20-22^{\circ} \mathrm{C}$ with $6 \mu \mathrm{mol} / \mathrm{l}$ fluo-4 AM. Thereafter, cells were superfused with Tyrode solution at $20-22^{\circ} \mathrm{C} . \mathrm{Ca}^{2+}$ sparks were assessed with a confocal microscope (Nikon Diaphot Eclipse TE2000 inverted microscope equipped with a confocal scanhead, Bio-Rad MicroRadiance 2000, and a $\times 60$ waterimmersion objective) in line-scan mode. Cells were scanned repeat- edly along their long axis at a rate of 166 lines/s. A Coherent sapphire laser was used to excite the dye at $488 \mathrm{~nm}$, and emitted fluorescence was measured at $>515 \mathrm{~nm} . \mathrm{Ca}^{2+}$ sparks were identified and analyzed with ImageJ software (National Institutes of Health) using the Sparkmaster plugin. Parameters analyzed were spark frequency, amplitude, duration to half-decay, and width at half-decay $(61,62) . \mathrm{Ca}^{2+}$ spark mass and spark leak were calculated as previously described (25) as

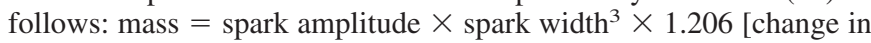
fluorescence/initial fluorescence $\left.\left(\Delta \mathrm{F} / \mathrm{F}_{0} \cdot \mu \mathrm{m}^{3}\right)\right]$ and $\mathrm{SR} \mathrm{Ca}^{2+}$ spark leak $=$ spark mass $\times$ spark frequency $\left(\Delta \mathrm{F} / \mathrm{F}_{0} \cdot \mu \mathrm{m}^{3} \cdot \mathrm{s}^{-1}\right)$.

Single myocyte electrophysiology. Single myocytes were impaled with sharp microelectrodes containing $0.6 \mathrm{~mol} / \mathrm{l} \mathrm{KCl}$ (resistance: $20-30 \mathrm{M} \Omega$ ). Cells were superfused with Tyrode solution at $37^{\circ} \mathrm{C}$, and APs were stimulated via an AxoClamp 2B amplifier (Axon Instruments) in bridge mode by the injection of 2-ms current pulses just above threshold amplitude at stimulation frequencies from 1 to $9 \mathrm{~Hz}$.

L-type $\mathrm{Ca}^{2+}$ current $\left(I_{\mathrm{CaL}}\right)$ was recorded in voltage-clamped myocytes using the switch-clamp technique with a switching frequency of $3 \mathrm{kHz}$. Myocytes were held at $-40 \mathrm{mV}$ to inactivate $\mathrm{Na}^{+}$current, and 0.1 $\mathrm{mmol} / \mathrm{l} \mathrm{BaCl}_{2}$ and $5 \mathrm{mmol} / \mathrm{l}$ 4-aminopyridine were used to block $\mathrm{K}^{+}$ currents (inward rectifier and transient outward $\mathrm{K}^{+}$currents, respec-

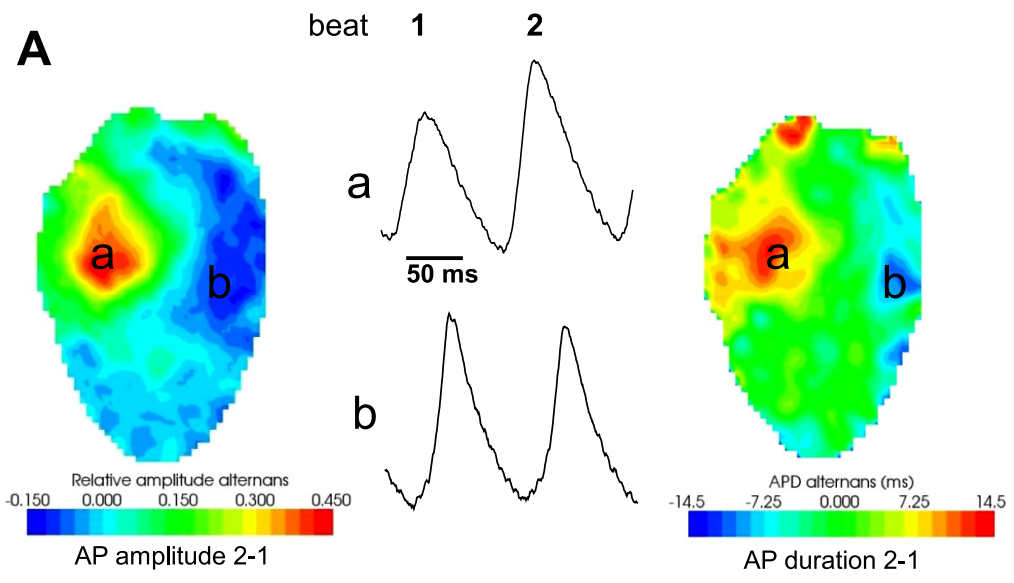

B
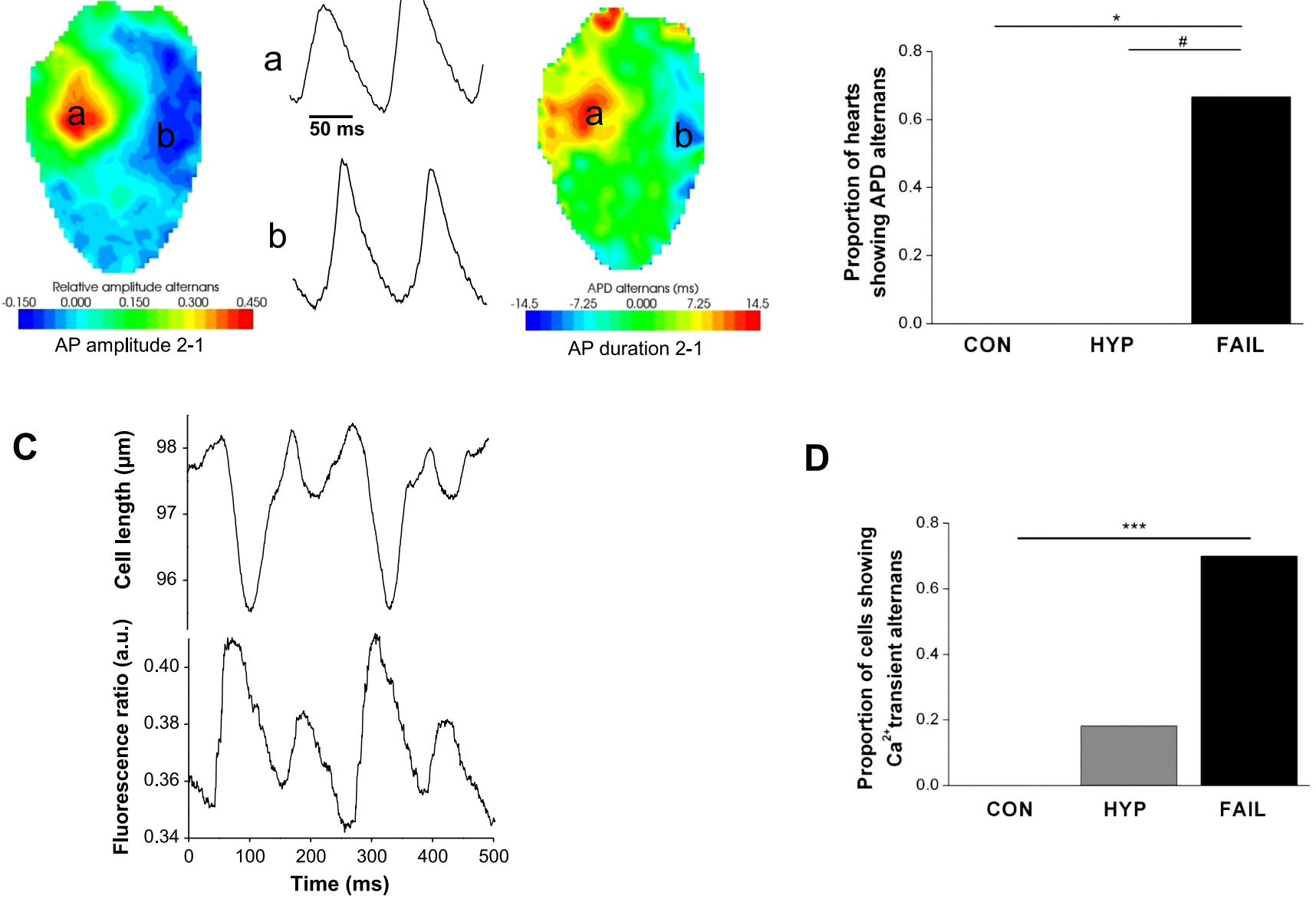

D

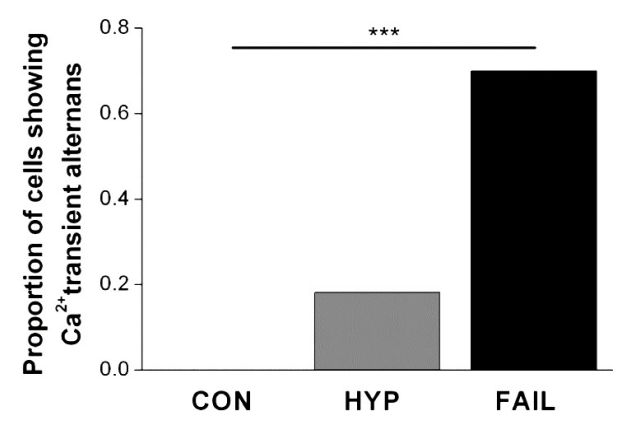

Fig. 4. Electrical and $\mathrm{Ca}^{2+}$ alternans in hearts of MCT-treated rats. A: difference in AP amplitude (left) and APD (right) between two successive beats (beats 1 and 2) from two regions ( $a$ and $b$ ) of a RV from a FAIL heart. APs are shown between the two maps. Each region displays amplitude and duration alternans out of phase (discordant) with each other. $B$ : proportion of hearts showing APD alternans from $N=5$ CON, 6 RV hypertrophied (HYP), and 6 FAIL hearts. $* P<0.05$ vs. CON; \#P $<0.05$, HYP vs. FAIL. As the severity of the MCT treatment increased, the probability of inducing electrical alternans increased $C$ : cell shortening and intracellular $\mathrm{Ca}^{2+}$ concentration $\left(\left[\mathrm{Ca}^{2+}\right]_{\mathrm{i}}\right)$ transients measured simultaneously in a single RV myocyte from a FAIL heart stimulated at a frequency of $9 \mathrm{~Hz}$. The myocyte displayed $\left[\mathrm{Ca}^{2+}\right]_{\mathrm{i}}$ transient and shortening alternans. $D$ : proportion of myocytes showing alternans from $n=18 \mathrm{CON}, 14 \mathrm{HYP}$, and 14 FAIL myocytes, $N=3$ hearts/group. $* * * P<0.001$ vs. CON. Alternans were provoked in FAIL myocytes but not in CON myocytes. 
tively). Steady-state $I_{\mathrm{CaL}}$ was elicited by a 100 -ms depolarizing step to 0 $\mathrm{mV}$ and was measured as the difference between the peak inward current and the current at the end of the depolarizing step. The time constant of inactivation was measured by fitting a single exponential to the decaying $I_{\mathrm{CaL}}$. The voltage dependence of $I_{\mathrm{CaL}}$ was assessed by depolarizing the cell from -40 to $+60 \mathrm{mV}$ in $10-\mathrm{mV}$ increments of 300 -ms duration. $\mathrm{Ca}^{2+}$ current availability was assessed by clamping back to $-40 \mathrm{mV}$ for $10 \mathrm{~ms}$ before a test pulse to $0 \mathrm{mV}$ was applied. Current was normalized to cell capacitance and expressed as $\mathrm{pA} / \mathrm{pF}$. All data were acquired with an Axon Digidata at a 5-kHz sampling rate and analyzed with pCLAMP 9.2 software (Axon Instruments).

Statistical analysis. Data are expressed as means \pm SE. Statistical differences between groups were tested with unpaired $t$-tests, one- or two-way ANOVA, or linear regression as appropriate. Statistically significant difference was assumed when $P<0.05$. Animal, heart, and myocyte numbers for each experiment are given in the relevant figures/tables.

\section{RESULTS}

Cardiac function in $R V$ failure. Echocardiographic recordings from anesthetized animals showed a significant depression in heart rate and function after 3 wk of failure treatment. PAAT, normalized to cardiac CL [a noninvasive index of pulmonary artery systolic pressure $(20,30)]$, was significantly reduced in FAIL animals. In the RV, wall thickness and end-diastolic diameter were increased, whereas RVFS was decreased. The LV showed a reduction in diameter, contractility, and aortic outflow. Thus, FAIL rats displayed both RV and LV insufficiency after $3 \mathrm{wk}$ of treatment (Fig. 1 and Table 1). There was an increase in the heart weight-to-body weight ratio, lung weight-to-body weight ratio, and $\mathrm{RV}$-to-LV weight ratio $(\mathrm{CON}<$ HYP and FAIL animals; Table 2).

Changes in the ECG with RV failure. ECGs were recorded by radio telemetry in conscious, unrestrained animals (Fig. 2A). After 3 wk of treatment, the R-R interval of FAIL animals was significantly shorter that of than CON animals (Fig. 2B), and hence heart rate was faster, in contrast to measurements made in anesthetized animals (see DISCUSSION). There were no significant differences in QRS durations between CON and FAIL animals (Fig. $2 C$ ). The QT interval of FAIL animals was prolonged at both 15 and $>21$ days (Fig. $2 D$ ). At $>21$ days, $\mathrm{T}_{\mathrm{pe}}$ was significantly prolonged (Fig. 2E). Lengthening of the QT interval is consistent with a prolongation of the mean APD and increased $T_{p e}$ with increased global dispersion of APD (see below).

T-wave alternans were recorded in some conscious, unrestrained FAIL animals (Fig. 3A). Alternans of both T-wave amplitude and QT interval were observed (Fig. $3 B$ ). When alternans were quantified as a $4 \%$ difference in successive amplitude for at least 10 consecutive beats, alternans of $\mathrm{T}$ wave height (Fig. 3C) and QT interval (Fig. 3D) comprised $>9 \%$ of measured beats in two (QT interval) or three (T-wave amplitude) of seven FAIL animals but $<1 \%$ of beats in six (QT interval) or seven (T-wave amplitude) of seven CON animals (13,000-22,000 beats were analyzed from each heart). Ventricular ectopic beats, measured in the same recordings, were rare: four events in total from three of seven FAIL animals and two events in total from one of seven $\mathrm{CON}$ animals. The occurrence of T-wave alternans could not be correlated with other
A

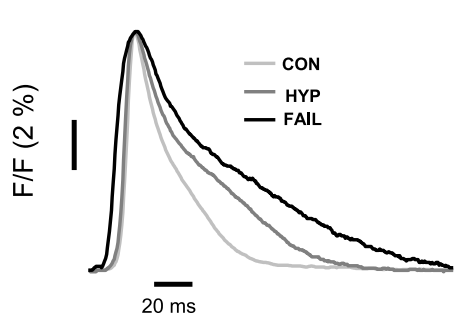

B

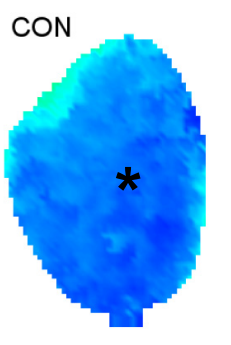

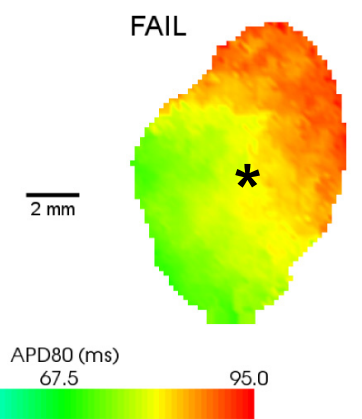

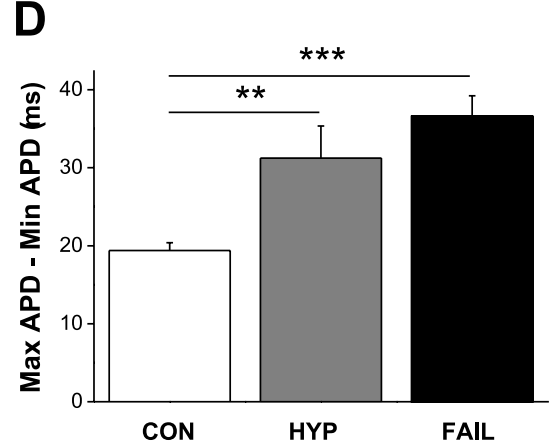

E

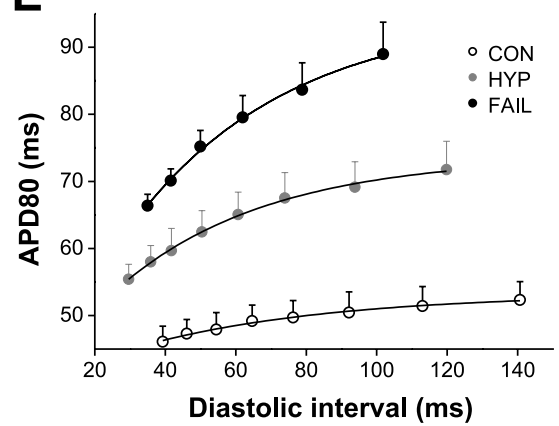

C
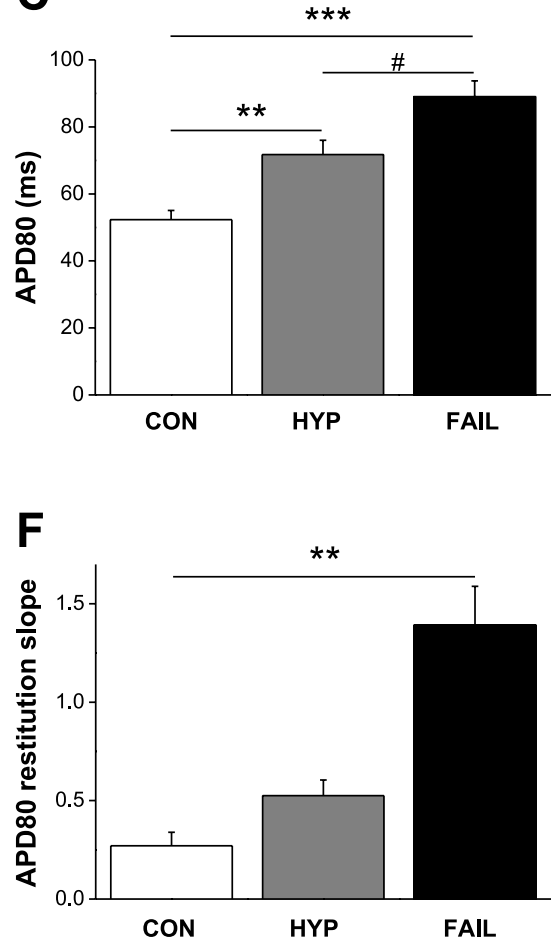

Fig. 5. Optical mapping of APs in RVs of CON and MCT-treated rats. A: optical APs recorded from the RV midline in a representative CON, HYP, and FAIL heart. $B$ : color-coded APD at $80 \%$ repolarization (APD 80 ) map over the surface of the RV at a resolution of $0.25 \mathrm{~mm}^{2}$ from a representative CON and FAIL heart. $C$ : $\mathrm{APD}_{80}$ measured at the RV midline (* in B). D: $\mathrm{APD}_{80}$ dispersion (maximum APD - minimum APD) in each heart. E: dynamic APD 80 restitution. $F$ : maximum slope of the $\mathrm{APD}_{80}$ restitution curve. Data are means $\pm \mathrm{SE}$ for $N=5 \mathrm{CON}, 6 \mathrm{HYP}$, and $6 \mathrm{FAIL}$ hearts. $* * P<0.01$ and $* * * P<0.001$ vs. CON; $\# P<0.05$, HYP vs. FAIL. As the severity of the MCT treatment increased, APD increased and APD restitution steepened. 
parameters of the ECG, such as R-R interval. However, the three animals showing $\mathrm{T}$-wave alternans appeared to be the most severely affected by MCT; they had the three largest heart weightto-body weight ratios and the three lowest body temperatures of the seven FAIL animals at the experimental end point.

Alternans in isolated hearts and single myocytes. We next established whether correlates of in vivo T-wave alternans could be identified in isolated hearts and single myocytes. Electrical activity was measured by optical mapping in isolated hearts. AP alternans were observed in FAIL hearts paced above $10 \mathrm{~Hz}$. Figure $4 A$ shows alternans of both AP amplitude and APD in two regions of the same RV in a FAIL heart. Alternans in the two regions were out of phase and therefore discordant. Alternans occurred in four of six FAIL hearts and were always discordant. One FAIL heart showed a transition from alternans to a 30 -s period of nonsustained fibrillation during pacing at $12 \mathrm{~Hz}$. Alternans were not observed in HYP or CON hearts; thus, there was a significant difference in the occurrence of AP alternans (CON and HYP < FAIL hearts; Fig. 4B).

APD alternans have been associated with dysfunctional $\mathrm{Ca}^{2+}$ homeostasis, resulting in $\left[\mathrm{Ca}^{2+}\right]_{\mathrm{i}}$ and contractile alternans. When single RV myocytes were stimulated to contract at 7-9 Hz, CON myocytes did not display alternans, but RV myocytes from FAIL hearts did (Fig. 4C). Only one in six LV FAIL myocytes developed alternans. The proportion of RV FAIL myocytes displaying alternans was significantly greater than CON myocytes (Fig. 4D). Thus, the increased presence of
A

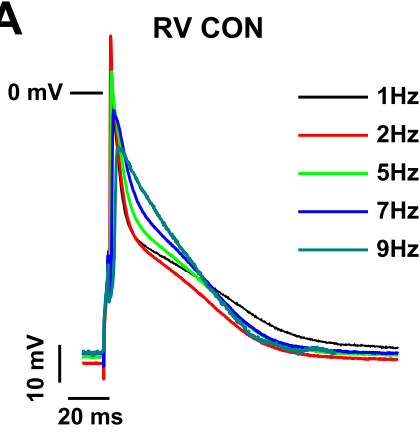

D

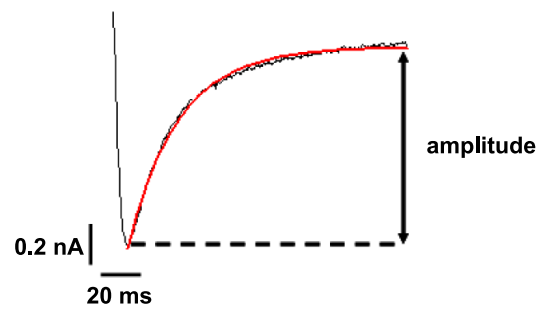

G

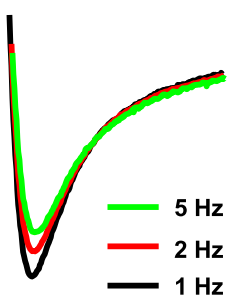

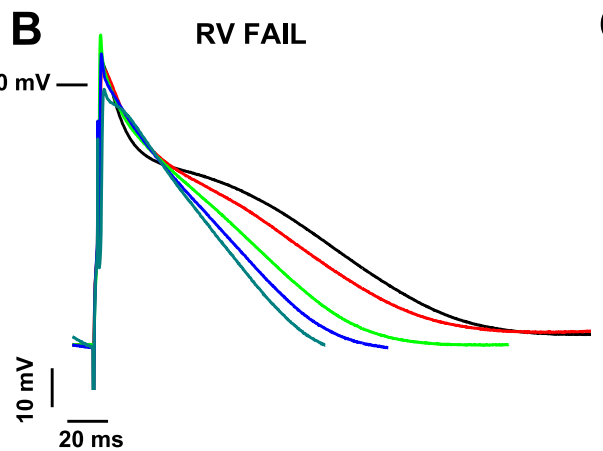

C
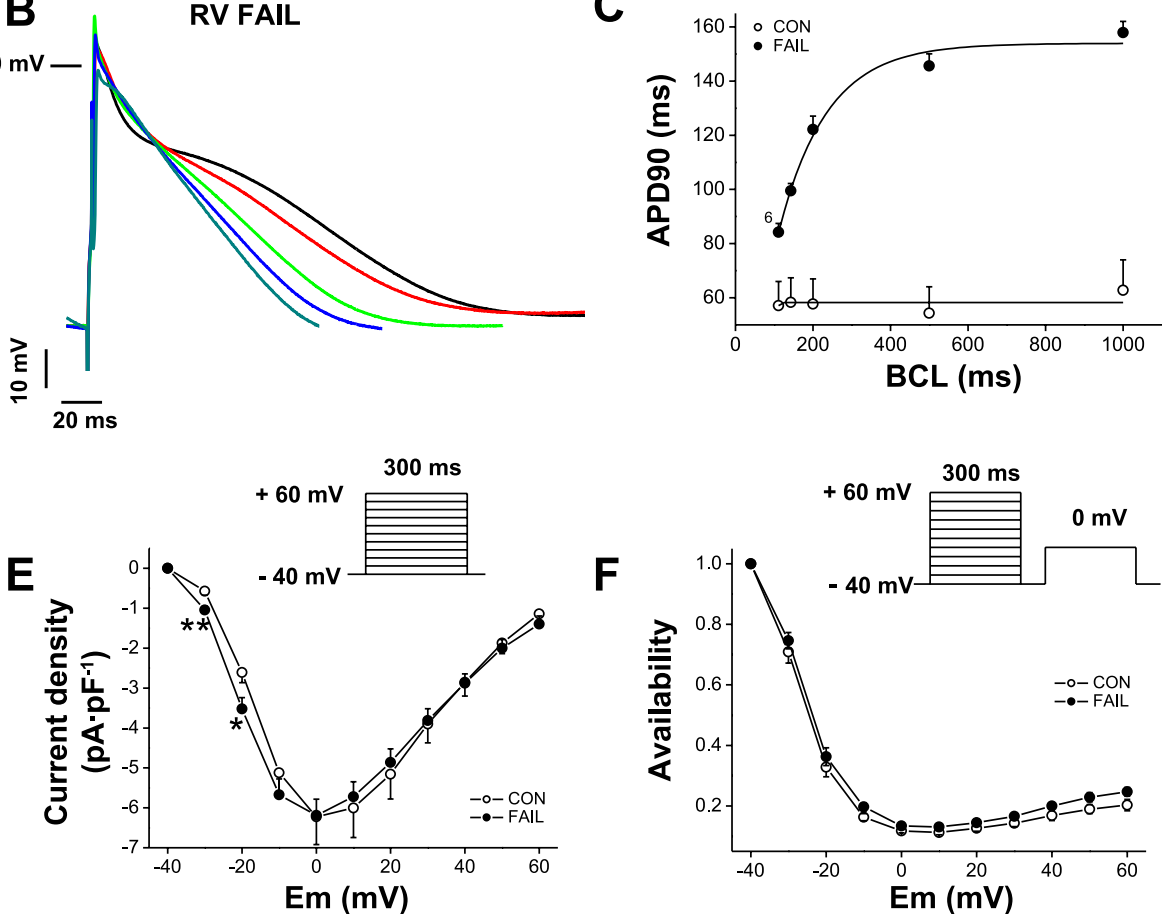

H

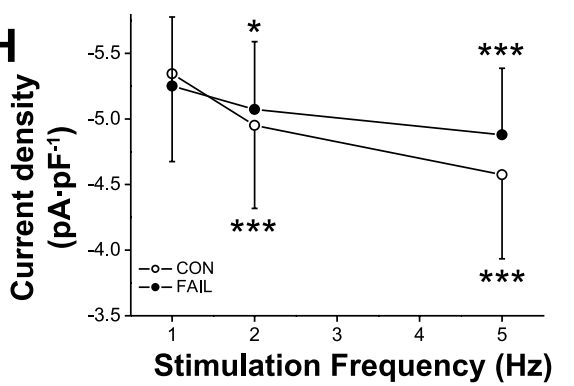

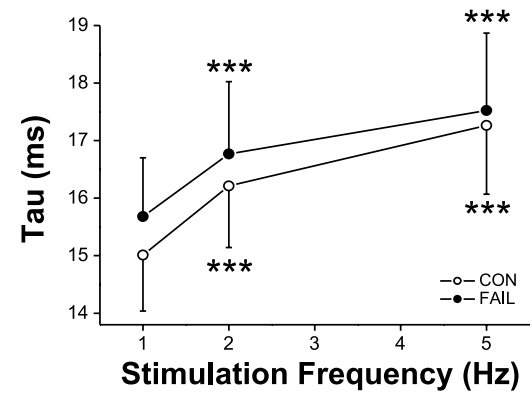

Fig. 6. APs and L-type $\mathrm{Ca}^{2+}$ currents $\left(I_{\mathrm{CaL}}\right)$ in single RV myocytes from CON and MCT-treated rats. $A$ and $B$ : intracellular membrane potential from a representative CON $(A)$ and FAIL $(B)$ RV myocyte at stimulation frequencies between 1 and $9 \mathrm{~Hz}$. $C$ : APD at $90 \%$ repolarization $($ APD 90 ) restitution curve for CON and FAIL myocytes. Data are means \pm SE; $n=3$ CON and 8 FAIL myocytes. Consistent with optically recorded APs in whole hearts, APs in single FAIL RV myocytes displayed a longer APD $(P<0.001$ at all frequencies $)$ and a steeper restitution curve than CON myocytes $(P<0.001)$. BCL, basic cycle length $D$ : representative $I_{\mathrm{CaL}}$ evoked by a depolarization from -40 to $0 \mathrm{mV}$. The red curve shows the exponential fit used to calculate the time constant of inactivation. $E$ and $F$ : current-voltage $\left(E_{\mathrm{m}}\right)$ relationship of $I_{\mathrm{CaL}}(E)$ and $I_{\mathrm{CaL}}$ availability $(F)$ in CON and FAIL myocytes stimulated at $1 \mathrm{~Hz}$. Schematic voltage protocols are shown above the data. $G$ : representative trace showing the negative effect of increasing stimulation frequency on the amplitude of $I_{\text {CaL. }} H$ and $I$ : mean data for the effect of stimulation frequency on $I_{\mathrm{CaL}}$ density $(H)$ and the $I_{\mathrm{CaL}}$ time constant of inactivation $($ tau; $I)$. Data are means \pm SE. $* P<0.05$, $* * P<0.01$, and $* * * P<0.001$ vs. CON in $E$ and vs. $1 \mathrm{~Hz}$ in $H$ and $I ; n=12$ CON and 15 FAIL myocytes from $N=3$ CON and 5 FAIL hearts. The effect of increased stimulation frequency was not statistically different between CON and FAIL myocytes. 
Fig. 7. Optical mapping of conduction velocity (CV) in RVs of CON and MCT-treated rats. A: colorcoded activation times across a representative RV surface. $B: \mathrm{CV}$ at a stimulation frequency of $5 \mathrm{~Hz}$ in CON, HYP, and FAIL hearts measured at the $\mathrm{RV}$ midline ( $*$ in $A$ ). $C$ : $\mathrm{CV}$ restitution curves in CON, HYP, and FAIL hearts. $D$ : slope of the CV restitution curve from CON, HYP, and FAIL hearts. Data are means $\pm \mathrm{SE}$ for $N=5 \mathrm{CON}, 6$ HYP, and 6 FAIL hearts. $* P<0.05$ and $* * * P<$ 0.001 vs. CON; $\# P<0.05$, HYP vs FAIL. As the severity of the MCT treatment increased, CV restitution became steeper.
A
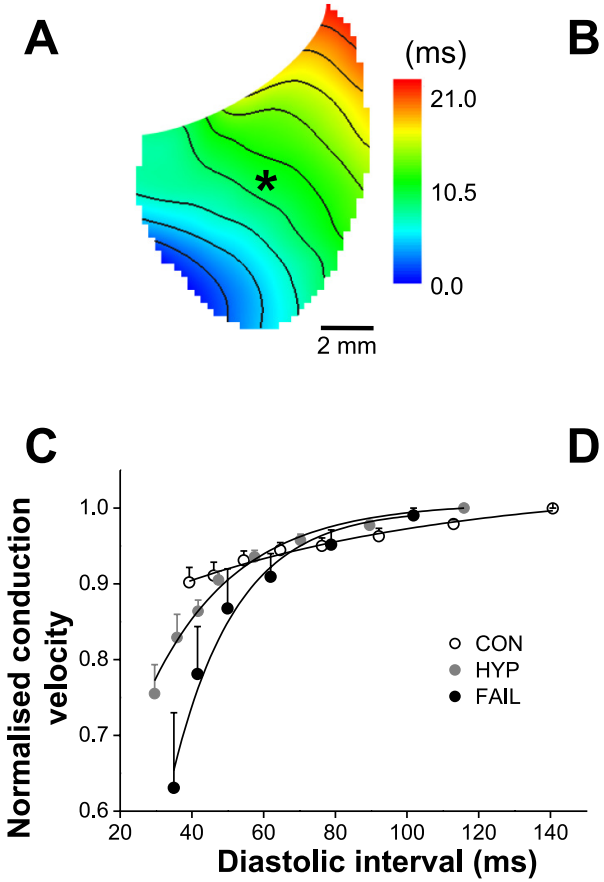

B



D

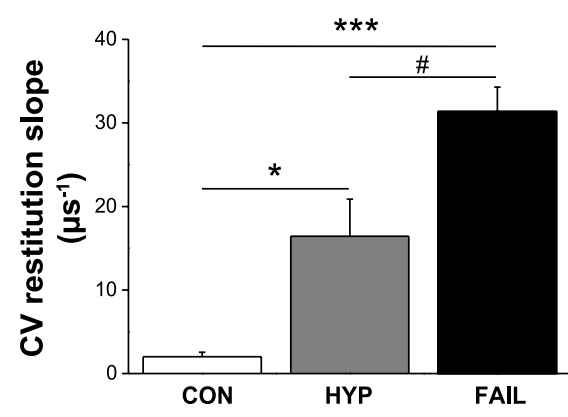

alternans in FAIL animals could be traced from single myocytes to isolated whole hearts and to the ECG in vivo.

Electrical restitution as a mechanism of alternans. Optical mapping was used to measure APD in isolated hearts (Fig. 5A). $\mathrm{APD}_{80}$ was mapped across the whole RV epicardial surface (Fig. $5 B$ ). At a pacing frequency of $5 \mathrm{~Hz}$, mean $\mathrm{APD}_{80}$ at the midregion (asterisk in Fig. $5 B$ ) increased (with $\mathrm{CON}<\mathrm{HYP}<$ FAIL hearts; Fig. 5C). We observed a significant correlation $\left(R^{2}=0.83, P<0.001\right)$ between the degree of cardiac hypertrophy (heart weight-to-body weight ratio) and $\mathrm{APD}_{80}$ (data not shown). APD dispersion was also increased (CON $<$ HYP and FAIL; Fig. 5D). Pacing frequency was increased at intervals to $13 \mathrm{~Hz}$ to measure dynamic APD restitution (Fig. 5E); the slope of the APD restitution curve was significantly steeper in the FAIL group than in the CON and HYP groups (Fig. $5 F$ ). AP recordings from single myocytes revealed that steeper APD restitution was an intrinsic property of FAIL myocytes (Fig. 6, $A-C$ ). Both increased APD dispersion and increased slope of APD restitution have been reported to be associated with an increased occurrence of alternans (see DISCUSSION).

We hypothesized that modification of $I_{\mathrm{CaL}}$ might explain the steeper APD restitution and altered $\mathrm{Ca}^{2+}$ handling of FAIL hearts and myocytes. However, we observed no differences in either the current density or rate of inactivation of $I_{\mathrm{CaL}}$ between CON and FAIL myocytes as stimulation frequency was increased (Fig. 6, $D-I$ ).

Optical mapping was also used to measure CV (Fig. 7A). At a pacing frequency of $5 \mathrm{~Hz}, \mathrm{CV}$ was not significantly different between the three groups of hearts (Fig. 7B). However, as pacing frequency increased, we observed changes in $\mathrm{CV}$ restitution (Fig. 7C). The slopes of these relationships were significantly different between the three groups of hearts $(\mathrm{CON}<\mathrm{HYP}<$ FAIL hearts; Fig. 7D).

Increased fiber disarray in FAIL hearts. Cardiac structure was investigated by DT-MRI in randomly selected hearts from each group after optical mapping (Fig. 8A). RV wall thickness was significantly increased in FAIL hearts with no difference in the range of fiber angles across the ventricle (Table 3). Therefore, the gradient of the fiber angle change was significantly shallower in the RV of FAIL hearts than the other two groups or FAIL LV (Fig. $8 B$ and Table 3). In addition, there was significantly greater disarray of fibers from RV FAIL hearts, as indexed by the $R^{2}$ of the fiber helix angle against position (Fig. $8 B$ and Table 3 ). The level of fiber disarray was significantly correlated with the heart weight-to-body weight ratio and $\mathrm{APD}_{80}$ at $5 \mathrm{~Hz}$ (Fig. 8C) but not with APD dispersion or CV.

Dysfunctional $\mathrm{SR} \mathrm{Ca}^{2+}$ release as a mechanism of alternans. The amplitude of $\mathrm{Ca}^{2+}$ transients evoked by electrical stimulation at $5 \mathrm{~Hz}$ was compared with that evoked by rapid exposure to $20 \mathrm{mmol} / \mathrm{l}$ caffeine (Fig. 9A) to assess SERCA function and $\mathrm{SR} \mathrm{Ca}^{2+}$ release. In FAIL cells compared with $\mathrm{CON}$ cells, there was a significant increase in $\mathrm{SR} \mathrm{Ca}^{2+}$ load (Fig. 9B) and SR release fraction (Fig. 9C) and a decrease in both $\mathrm{Na}^{+} / \mathrm{Ca}^{2+}$ exchanger (plus other $\mathrm{Ca}^{2+}$ removal pathways, excluding SERCA; Fig. 9D) and SERCA activity (Fig. 9E). $\mathrm{Ca}^{2+}$ spark parameters were measured (Fig. $10 A$ and Table 4). $\mathrm{Ca}^{2+}$ spark mass was significantly increased in both HYP and FAIL myocytes compared with CON myocytes (Fig. 10B), and $\mathrm{SR} \mathrm{Ca}^{2+}$ spark leak was significantly greater in FAIL myocytes $(\mathrm{CON}<\mathrm{HYP}<\mathrm{FAIL}$ myocytes; Fig. 10C) due to increased spark width and frequency (Table 4). The amplitude of $\left[\mathrm{Ca}^{2+}\right]_{\mathrm{i}}$ transients and cell shortening at stimulation frequencies from 1 to $9 \mathrm{~Hz}$ were measured (Fig. 11). Compared with CON myocytes, FAIL myocytes displayed significantly larger amplitudes at $1 \mathrm{~Hz}$, but these fell steeply as stimulation frequency was increased.

\section{DISCUSSION}

A whole animal to single myocyte approach was used to investigate which established arrhythmic mechanisms were present in the MCT-induced model of pulmonary artery 
A

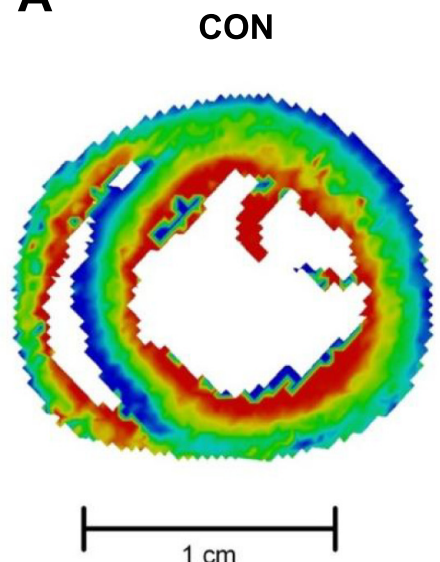

B

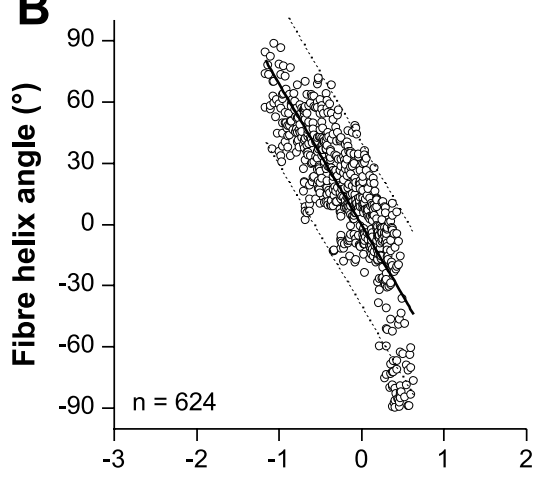

HYP

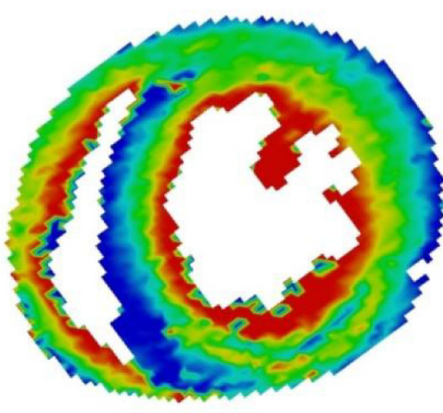

$-60^{\circ} \square 60^{\circ}$

Fibre helix angle

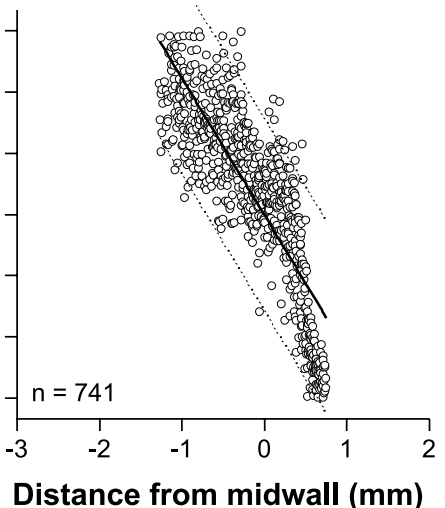

FAIL
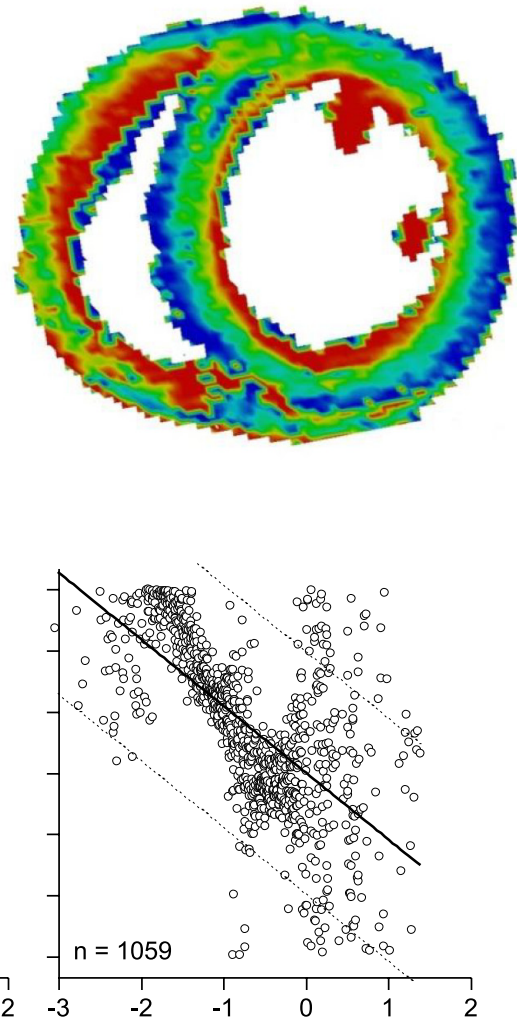
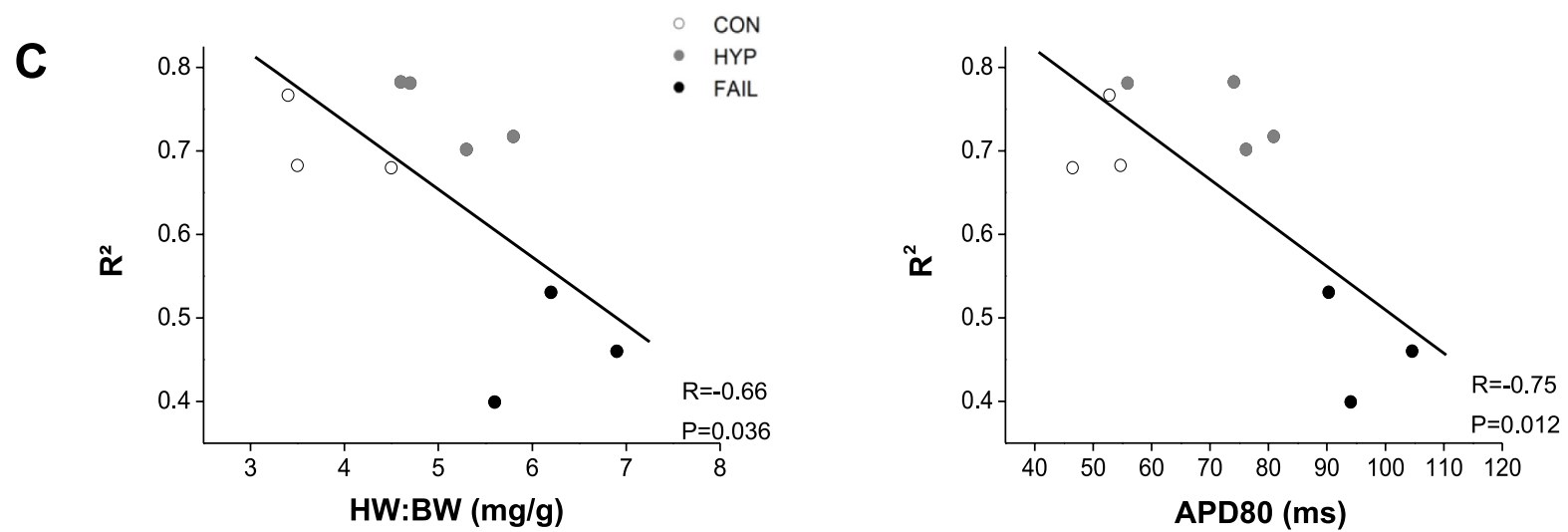

Fig. 8. Diffusion tensor (DT)-MRI of myocardial fiber orientation in CON and MCT-treated rats. A: equatorial short-axis slices from representative CON, HYP, and FAIL hearts showing color-coded fiber inclination (helix) angle. Angles of -90 to $-60^{\circ}$ and from +60 to $+90^{\circ}$ are represented as -60 and +60 , respectively, for clarity. $B$ : fiber inclination (helix) angle as a function of transmural distance from the midwall for representative CON, HYP, and FAIL hearts. Data are from 2 -mm-thick and $15^{\circ}$-wide sectors from the equatorial RV free wall. Fiber angle rotation was less steep and fiber disarray increased in FAIL hearts (see Table 3). C: correlations between myocardial fiber disarray, as indexed by the $R^{2}$ of the fiber helix angle derived from DT-MRI imaging and the heart weight-to-body weight ratio (HW/BW; left) and $\mathrm{APD}_{80}$ at $5 \mathrm{~Hz}$ (right) The respective $R$ and $P$ values are shown. Data in $C$ are from $N=4 \mathrm{CON}, 4 \mathrm{HYP}$, and 3 FAIL hearts. Fiber disarray was significantly correlated with HW:BW and APD 80 .

hypertension at two stages of the disease. In animals with $\mathrm{RV}$ failure, steep electrical restitution, myofiber disarray, and dysfunction of SR $\mathrm{Ca}^{2+}$ handling were identified. Consistent with the presence of these mechanisms, $\left[\mathrm{Ca}^{2+}\right]_{\mathrm{i}}$ transient alternans and discordant AP alternans, established precursors of serious arrhythmias, could be provoked in isolated cells and hearts. Furthermore, T-wave alternans in the ECG of some conscious, unrestrained animals were seen. We suggest these mechanisms are the cause of the proarrhythmic substrate of this model (3).

Because we (3) have previously reported that AP remodeling in response to MCT is primarily RV rather than $\mathrm{LV}$, and because we did not see significantly elevated levels of $\mathrm{Ca}^{2+}$ alternans in LV myocytes from FAIL hearts, for brevity and 
Table 3. Characteristics of myocardial fiber orientation from DT-MRI of CON and monocrotaline-treated hearts

\begin{tabular}{|c|c|c|c|c|c|}
\hline & \multicolumn{2}{|c|}{ Wall Thickness, mm } & \multirow[b]{2}{*}{ Helix Range, ${ }^{\circ}$} & \multirow[b]{2}{*}{ Helix Slope, $\% / m m$} & \multirow[b]{2}{*}{$R^{2}$} \\
\hline & $\mathrm{mm}$ & $\mathrm{RV} / \mathrm{LV}$ & & & \\
\hline \multicolumn{6}{|l|}{$\overline{\mathrm{LV}}$} \\
\hline $\mathrm{CON}$ & $1.98 \pm 0.12$ & & $164 \pm 12$ & $-50 \pm 5.0$ & $0.90 \pm 0.04$ \\
\hline HYP & $2.13 \pm 0.21$ & & $139 \pm 11$ & $-60 \pm 11.0$ & $0.84 \pm 0.10$ \\
\hline FAIL & $2.20 \pm 0.18$ & & $135 \pm 14$ & $-45 \pm 2.7$ & $0.84 \pm 0.10$ \\
\hline \multicolumn{6}{|l|}{ RV } \\
\hline $\mathrm{CON}$ & $1.20 \pm 0.04$ & $0.62 \pm 0.05$ & $148 \pm 9$ & $-73 \pm 7.8$ & $0.72 \pm 0.05$ \\
\hline HYP & $1.63 \pm 0.14$ & $0.78 \pm 0.07$ & $141 \pm 5$ & $-70 \pm 7.0$ & $0.75 \pm 0.04$ \\
\hline FAIL & $1.97 \pm 0.12 *$ & $0.91 \pm 0.10$ & $128 \pm 12$ & $-37 \pm 3.6^{*}$ & $0.46 \pm 0.07 *$ \\
\hline
\end{tabular}

Values are means $\pm \mathrm{SE} ; N=4 \mathrm{CON}$ hearts, 4 HYP hearts, and 3 FAIL hearts. Shown are LV and RV wall thicknesses, fiber inclination (helix) angle ranges and slopes, and $R^{2}$ values for data from 2-mm-thick and $15^{\circ}$-wide sectors from the equatorial LV and RV free walls in CON, HYP, and FAIL hearts. Decreased $R^{2}$ is a measure of increased fiber disarray. ${ }^{*} P<0.05$ versus the CON group.

clarity, we have presented data predominantly from the RV at two stages of the disease. MCT treatment produces pulmonary hypertension, as we (and other groups) have previously demonstrated (e.g., Ref. 3). Here, we used PAAT normalized to cardiac CL as a serial, noninvasive index of increasing pulmonary artery systolic pressure $(20,30)$. Our indexes of dosedependent changes in cardiac size, function, and symptoms are consistent with previous studies using this model $(20,21,24)$. Compared with CON animals, FAIL animals displayed de- creased heart rates when anesthetized (see Table 1 and Refs. $21,24)$ and increased heart rates when conscious and unrestrained (see Fig. 2 and Ref. 51). We conclude that FAIL animals are more sensitive to anesthesia (see Ref. 21), like human sufferers of heart failure (7).

The increased QT interval in FAIL animals was mirrored by an increase in RV APD in both isolated whole hearts and single myocytes. The longer APD is thought to be due to decreased $\mathrm{K}^{+}$currents, principally transient outward and inward rectifier

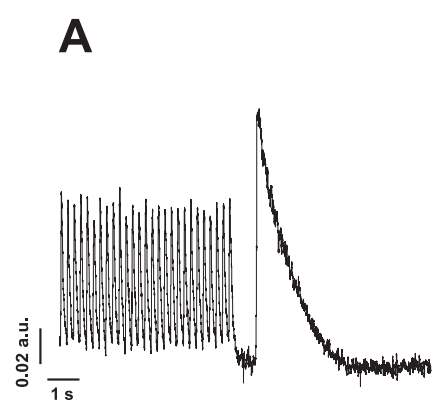

B

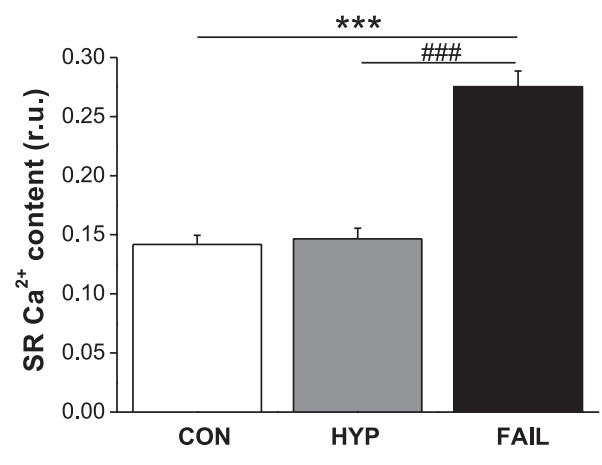

D

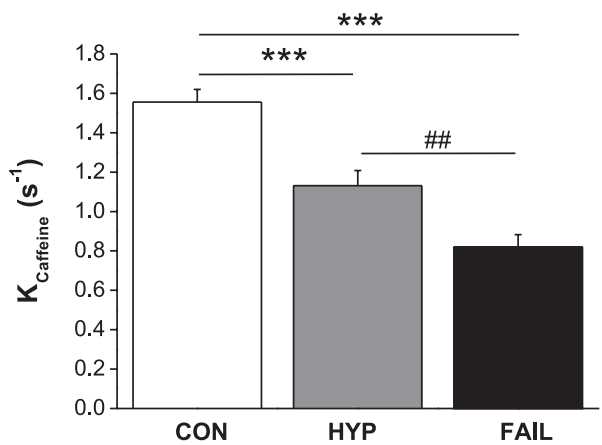

C

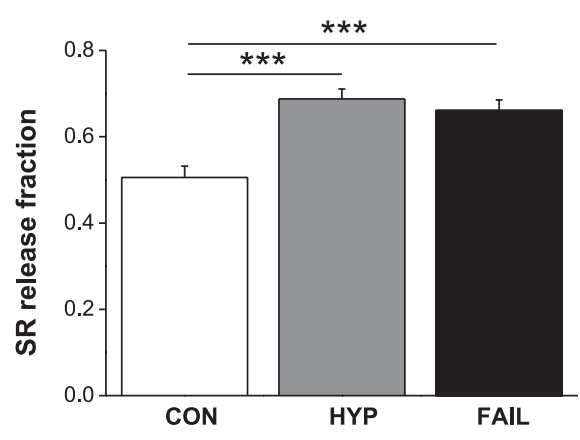

$\mathbf{E}$

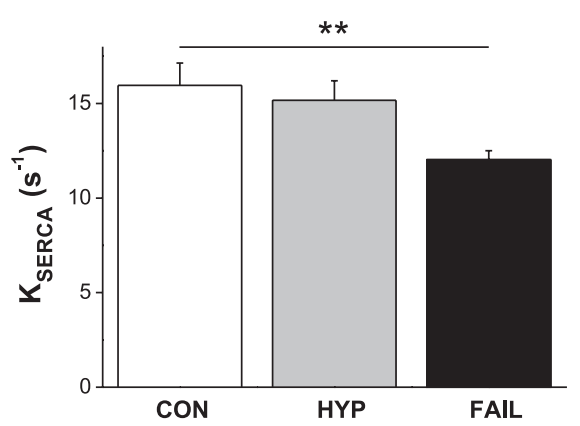

Fig. 9. Dysfunctional sarcoplasmic reticulum (SR) $\mathrm{Ca}^{2+}$ regulation in RV myocytes of MCT-treated rats. $A$ : $\left[\mathrm{Ca}^{2+}\right]_{\mathrm{i}}$ transients in a myocyte electrically stimulated at $5 \mathrm{~Hz}$. Stimulation was then stopped, and $20 \mathrm{mmol} / \mathrm{l}$ caffeine was rapidly applied to release $\mathrm{Ca}^{2+}$ from the SR. $B$ : SR Ca ${ }^{2+}$ content estimated from the amplitude of the caffeine-induced $\mathrm{Ca}^{2+}$ transient. $C$ : $\mathrm{SR} \mathrm{Ca}^{2+}$-release fraction calculated from the relative amplitude of the electrically and caffeine-induced $\mathrm{Ca}^{2+}$ transients. $D$ : estimate of function of the $\mathrm{Na}^{+} / \mathrm{Ca}^{2+}$ exchanger, based on the decay of the caffeine-induced Ca ${ }^{2+}$ transient $\left(K_{\text {caffeine }}\right)$. $E$ : sarco(endo)plasmic $\mathrm{Ca}^{2+}$-ATPase (SERCA) function, calculated from the difference between the time constant of decay of the electrically and caffeine-stimulated Ca ${ }^{2+}$ transients $\left(K_{\mathrm{SERCA}}\right) . n=11 \mathrm{CON}, 13 \mathrm{HYP}$, and $10 \mathrm{FAIL}$ myocytes from $N=4 \mathrm{CON}, 3 \mathrm{HYP}$, and 3 FAIL hearts. $* * P<0.01$ and $* * * P<0.001$ vs. CON; \#\#P<0.01 and \#\#\#P $<0.001, \mathrm{HYP}$ vs. FAIL. Evidence is presented for dysfunctional SR $\mathrm{Ca}^{2+}$ uptake and SR Ca ${ }^{2+}$-release fraction in FAIL myocytes. 

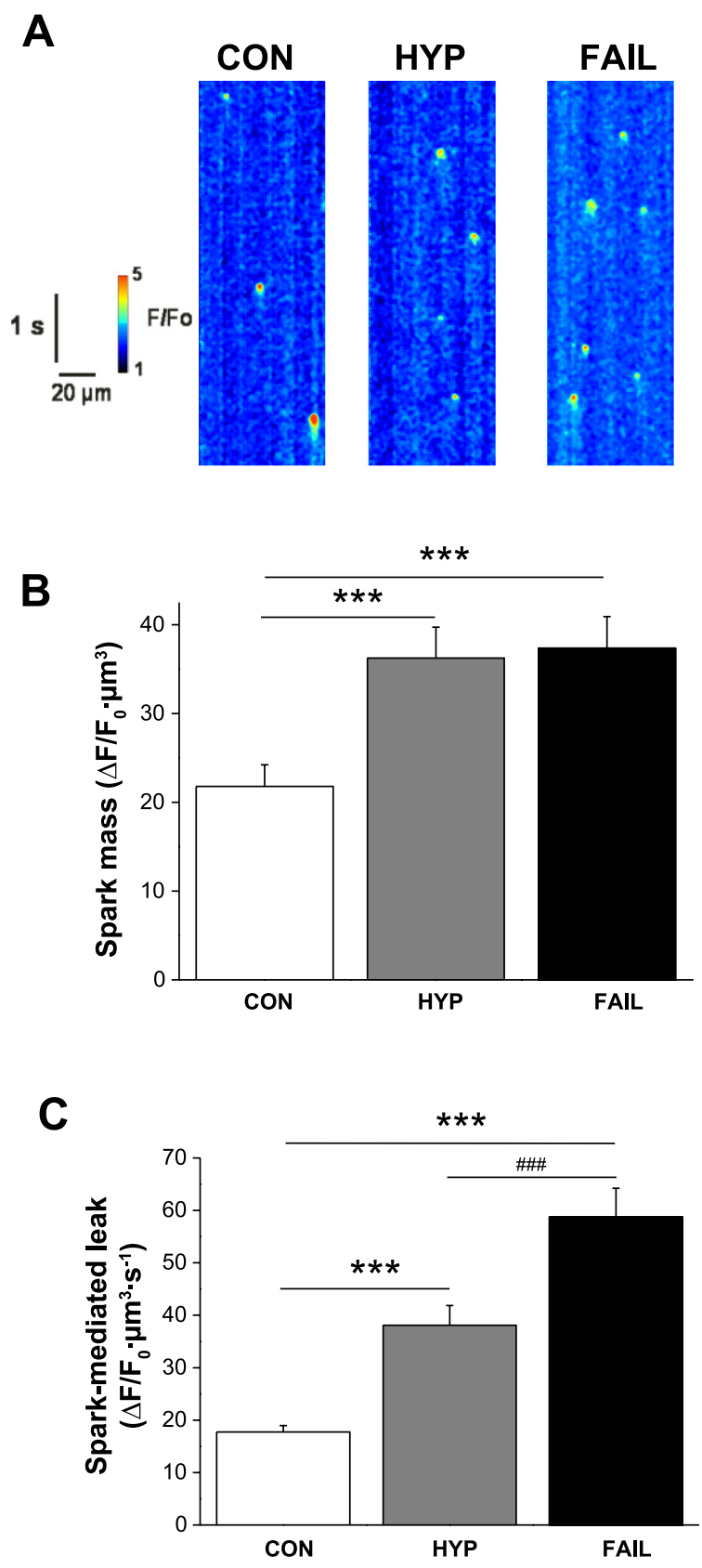

Fig. 10. $\mathrm{Ca}^{2+}$ spark properties in RV myocytes of MCT-treated rats. A: $\mathrm{Ca}^{2+}$ sparks measured by confocal microscopy in line-scan mode. Representative images from CON, HYP, and FAIL myocytes are shown. $B$ : $\mathrm{Ca}^{2+}$ spark mass calculated from individual spark amplitude and width. $C$ : spark-mediated leak (the product of spark mass and spark frequency; see Table 4). $n=152 \mathrm{CON}$, $138 \mathrm{HYP}$, and $152 \mathrm{FAIL} \mathrm{Ca}^{2+}$ sparks from $n=31 \mathrm{CON}, 32 \mathrm{HYP}$, and 24 FAIL myocytes from $N=3$ hearts/group. $* * * P<0.001$ vs. CON; \#\#\#P< 0.001 , HYP vs. FAIL. Evidence is presented for progressively increased SR $\mathrm{Ca}^{2+}$ leak in HYP and FAIL myocytes.

$\mathrm{K}^{+}$currents $(3,37,47)$. The QT interval may also be influenced by activation times across the myocardium, but the QRS duration of the ECG was not altered in FAIL hearts, indicating a relatively minor effect of activation time upon the changes in QT interval.

$T$-wave, $A P$, and $\left[\mathrm{Ca}^{2+}\right]_{i}$ alternans. Alternans have not been previously reported in MCT-treated animals. A major novel finding of our study is that the failing, hypertensive RV displays alternans, traceable from $\left[\mathrm{Ca}^{2+}\right]_{\mathrm{i}}$ transients in single myocytes, to discordant AP parameters in isolated hearts, to the T-wave of the in vivo ECG. Furthermore, these alternans coexist with mechanisms previously shown to provoke them (see below).

Presence of mechanisms that generate alternans. Increased electrical heterogeneity and steeper electrical restitution $(1,32$, 53) increase the probability of alternans and arrhythmias (see the Introduction and Refs. 1, 32, and 53). These properties were demonstrated in FAIL animals as an increase in $\mathrm{T}_{\mathrm{pe}}$ of the ECG, indicating increased global dispersion of APD $(2,44)$ and increased RV dispersion of APD in optically mapped, isolated FAIL hearts. The slope of APD restitution in FAIL hearts exceeded 1, a value linked with critical instability of APD and diastolic interval and with susceptibility to alternans and arrhythmias (49). Furthermore, we showed that the steeper APD restitution is an intrinsic property of FAIL RV myocytes. It is worth noting that optical AP amplitude alternans do not correspond to transmembrane AP amplitude alternans. Instead, they indicate alternating fluorescence intensity levels, which may be caused by intramural conduction alternans or even 2:1 conduction block (43).

Because there were no differences in $\mathrm{CV}$ at $5 \mathrm{~Hz}$ between groups, we conclude that the steeper $\mathrm{CV}$ restitution we observed in FAIL hearts is due to dynamic properties of the tissue, such as ion channel kinetics or ionic/metabolite distribution. Structural changes such as fiber orientation or fibrosis would be expected to affect $\mathrm{CV}$ at all stimulation frequencies. The observation of $\mathrm{CV}$ restitution and $\mathrm{AP}$ alternans at similar diastolic intervals is consistent with the AP alternans being discordant in nature (49). Uzzaman et al. (57) reported a lateralization of connexin43 expression and decreased longitudinal CV in MCT-treated hearts. In our study, CV was measured in a small RV midfree wall region primarily in the transverse fiber direction with respect to the pacing location (see Fig. 7A). Our results are therefore not inconsistent with this previous study (57).

Although changes in the levels of some key $\mathrm{Ca}^{2+}$-handling proteins have been measured in MCT-treated animals (e.g., Ref. 33), functional demonstration of $\mathrm{Ca}^{2+}$-handling dysregulation has not previously been reported. Alternans have been shown to be provoked by dysregulation of $\mathrm{SR} \mathrm{Ca}^{2+}$ uptake, load, and release (see the Introduction and Refs. 9, 13, 35, 38, 48, 49, and 60). We presented evidence for the presence of three of these mechanisms in our study: 1) decreased SERCA activity, as indicated by decreased $K_{\text {SERCA }}$ and consistent with the report of decreased SERCA protein levels in MCTtreated animals $(33) ; 2$ ) increased SR release fraction, consistent with increased SR $\mathrm{Ca}^{2+}$ content (see Fig. 9, $B$ and $C$ ); and 3) $\mathrm{SR} \mathrm{Ca}^{2+}$ leak, as assessed by $\mathrm{Ca}^{2+}$ spark leak, also consistent with increased SR $\mathrm{Ca}^{2+}$ load. Modifications of $\mathrm{Ca}^{2+}$ spark parameters are common in heart failure, but the changes in parameters, such as amplitude and frequency, differ between studies (8). $\mathrm{Ca}^{2+}$ alternans caused contractile alternans (see Fig. 4C), which have been described in pulmonary hypertensive patients (41).

Increased APD duration in FAIL cells is likely to contribute to the increase in $\mathrm{SR} \mathrm{Ca}^{2+}$ load and, in turn, to the increase in fractional $\mathrm{Ca}^{2+}$ release and $\mathrm{SR} \mathrm{Ca}^{2+}$ leak. However, we believe that this is not the sole reason for the changes in SR 
Table 4. Characteristics of $\mathrm{Ca}^{2+}$ sparks in myocytes from CON and monocrotaline-treated rats

\begin{tabular}{|c|c|c|c|}
\hline & $\mathrm{CON}$ & HYP & FAIL \\
\hline Frequency, sparks $\cdot 100 \mu \mathrm{m}^{-1} \cdot \mathrm{s}^{-1}$ ) & $0.71 \pm 0.06$ & $0.86 \pm 0.07$ & $1.27 \pm 0.13 *$ \\
\hline Amplitude, $\Delta \mathrm{F} / \mathrm{F}_{0}$ & $1.74 \pm 0.03$ & $1.67 \pm 0.02 \dagger$ & $1.52 \pm 0.03 *$ \\
\hline Width, $\mu \mathrm{m}$ & $2.08 \pm 0.04$ & $2.44 \pm 0.06^{*}$ & $2.57 \pm 0.06^{*}$ \\
\hline Duration, ms & $58.82 \pm 2.15$ & $66.48 \pm 2.98$ & $73.99 \pm 3.19 *$ \\
\hline Spark mass, $\left(\Delta \mathrm{F} / \mathrm{F}_{0}\right) \cdot \mu \mathrm{m}^{3}$ & $21.77 \pm 2.46$ & $36.24 \pm 3.47 *$ & $37.35 \pm 3.57 *$ \\
\hline Spark-mediated leak, $\left(\Delta \mathrm{F} / \mathrm{F}_{0}\right) \cdot \mu \mathrm{m}^{3} \cdot \mathrm{s}^{-1}$ & $17.75 \pm 1.22$ & $38.11 \pm 3.76^{* \dagger}$ & $58.75 \pm 5.48 *$ \\
\hline
\end{tabular}

Values are means $\pm \mathrm{SE} ; n=153 \mathrm{CON}, 138 \mathrm{HYP}$, and 152 FAIL spark events from $n=31 \mathrm{CON}, 32 \mathrm{HYP}$, and 24 FAIL myocytes from $N=3$ hearts/group. $\mathrm{Ca}^{2+}$ spark frequency, amplitude, width, and duration were recorded from RV myocytes from CON, HYP, and FAIL hearts. Spark mass was calculated as amplitude $\times$ width $^{3} \times 1.206$, and spark leak was calculated as mass $\times$ frequency. $\Delta \mathrm{F} / \mathrm{F}_{0}$, change in fluorescence/initial fluorescence. ${ }^{*} P<0.001$ vs. the CON group; $\uparrow P<0.001$, HYP group vs. FAIL group.

$\mathrm{Ca}^{2+}$ release in FAIL cells. Compared with CON cells, HYP cells showed an increase in the $\mathrm{SR} \mathrm{Ca}^{2+}$ release fraction and $\mathrm{SR} \mathrm{Ca}^{2+}$ spark leak but not an increase in $\mathrm{SR} \mathrm{Ca}^{2+}$ load, indicating that $\mathrm{SR} \mathrm{Ca}^{2+}$ load is not solely responsible for the changes in $\mathrm{SR} \mathrm{Ca}^{2+}$ release. In addition, previous studies in the MCT model (e.g., Ref. 33) have shown decreased expression of the ryanodine receptor, indicating an alteration in $\mathrm{SR} \mathrm{Ca}^{2+}$ release proteins.

An increase in $\mathrm{SR} \mathrm{Ca}^{2+}$ load and a decrease in SERCA activity are, in isolation, incompatible; therefore, the accumulation of $\mathrm{SR} \mathrm{Ca}^{2+}$ in FAIL myocytes may also be dependent upon factors such as $\mathrm{SR} \mathrm{Ca}^{2+}$ buffering and the extrusion of cytosolic $\mathrm{Ca}^{2+}$ by the $\mathrm{Na}^{+} / \mathrm{Ca}^{2+}$ exchanger, which we found was depressed (Fig. 9D). Although decreased contraction and $\left[\mathrm{Ca}^{2+}\right]_{\mathrm{i}}$ transients are typically seen in heart failure (5), this is not always the case; e.g., Mork et al. (42) found that viable myocytes in a failing LV infarction model had increased $\left[\mathrm{Ca}^{2+}\right]_{\mathrm{i}}$ transients and contraction. In our FAIL hearts in vivo, myocytes may also exist in a more fibrotic structure $(20,33)$. Events such as apoptosis and defective energy utilization can also contribute to heart failure independently of myocyte contractility (28). The steep rate-dependent fall in both $\left[\mathrm{Ca}^{2+}\right]_{\mathrm{i}}$ and cell shortening amplitude in FAIL myocytes is, however, a characteristic of heart failure (28) and is compatible with decreased SERCA function.

We observed no change in the peak density of $I_{\mathrm{CaL}}$, in agreement with the observations of Lee et al. (36) in the MCT model and Piacentino et al. (46) in failing human myocytes. The increase in $I_{\mathrm{CaL}}$ density at -30 and $-20 \mathrm{mV}$ we report may be related to increased T-type $\mathrm{Ca}^{2+}$ current (55) and T-type mRNA (3) previously observed in the MCT model. To our knowledge, the role of $I_{\mathrm{CaL}}$ in the alteration of APD restitution in heart failure has not previously been investigated. We hypothesized that in response to elevated stimulation frequency, increased inactivation of $I_{\mathrm{CaL}}$ might be a linking factor in the steeper APD restitution of FAIL hearts and to $\mathrm{Ca}^{2+}$-handling dysregulation, in particular the steep rate-dependent fall in $\left[\mathrm{Ca}^{2+}\right]_{i}$ transient amplitude; however, the data do not support either of these hypotheses.

Structural remodeling. Measurement of myocardial fiber orientation using the primary eigenvector angle from the DTMRI analysis has been validated, and the change in fibre helix angle across the ventricular wall has been shown to have a broadly linear profile (52). Our use of the $R^{2}$ of this linear relationship is a novel quantitative indicator of fiber angle heterogeneity or disarray, from which we concluded that myofiber disarray was increased in FAIL animals. This may be related to increased fibrosis (20).

Progressive remodeling. For most parameters studied e.g., APD and CV restitution, fiber disarray, SERCA function, and $\mathrm{Ca}^{2+}$ spark leak, the HYP state represents an intermediate between the CON and FAIL states, indicating that these dysfunctional mechanisms are developing before the appearance of heart failure. The incidence of APD and $\mathrm{Ca}^{2+}$ alternans was much lower in HYP hearts than in FAIL hearts, but fractional $\mathrm{SR} \mathrm{Ca}^{2+}$ release and APD dispersion were not different between HYP and FAIL hearts. This may indicate these mechanisms were not central to the development of alternans. In contrast, SR $\mathrm{Ca}^{2+}$ load, fiber disarray, and APD restitution slope were smaller in HYP than in FAIL hearts. It is particularly interesting to compare the slope of the APD restitution curve, which was $>1$ in FAIL hearts but $<1$ in HYP hearts, as
Fig. 11. Effect of stimulation frequency on intracellular $\mathrm{Ca}^{2+}$ transients and cell shortening in single $\mathrm{RV}$ myocytes from $\mathrm{CON}$ and MCT-treated rats. $A$ and $B$ : intracellular $\mathrm{Ca}^{2+}$ transient amplitude (340-to-380-nm ratio units; A) and cell shortening [\%resting cell length (RCL); B] in the same myocytes from CON, HYP, and FAIL hearts. $* * * P<0.001$, $* * P<0.01$, and $* P<0.05$ vs. CON; \#\#\#P< 0.001 , HYP vs. FAIL. $n=18$ CON, 14 HYP, and 14 FAIL myocytes or as indicated in the figure from $N=3$ hearts/group. Compared with CON myocytes, both parameters were significantly larger in HYP and FAIL myocytes but fell steeply as stimulation frequency increased in FAIL cells.
A

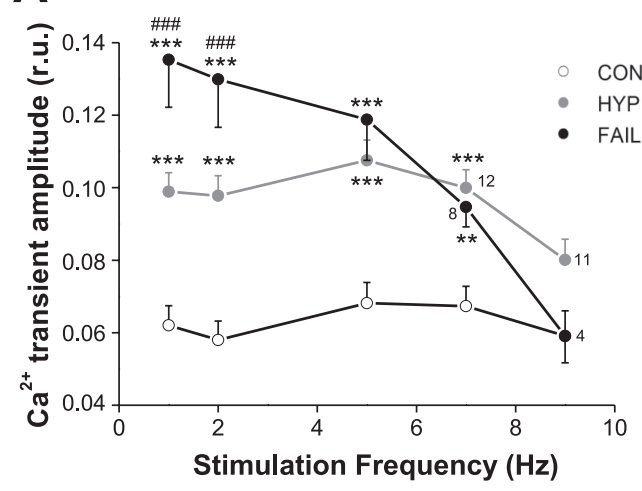

B

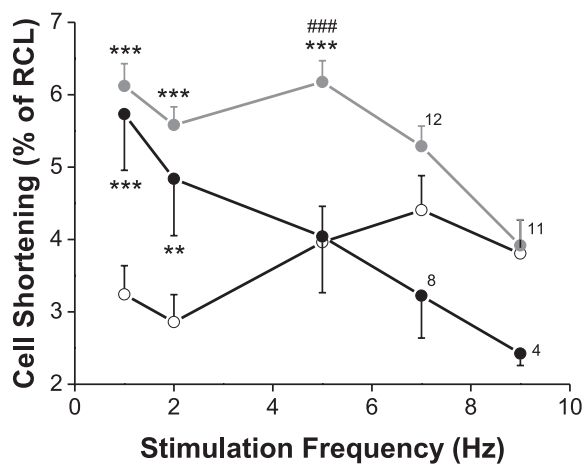


a slope of $>1$ is thought to be a critical factor in the development of alternans (49).

Study limitations. The electrophysiology of rodents is distinct from that of humans, and its applicability can be questioned. However, alterations in the ECG ventricular gradient and QT interval in response to MCT $(22,37,47)$ were similar to changes seen in humans with pulmonary hypertension (23, 26, 27); therefore, understanding the mechanisms causing these changes may be relevant to the clinical setting $(10,63)$.

The various uncoupling agents used in optical recording of APs have been reported to affect electrical activity in unique ways (39). However, we found that the differences between APD and the shape of APD restitution curves were qualitatively similar in either MCT or control preparations whether measured optically in BDM-treated whole hearts or in untreated single myocytes (this study) or by monophasic AP in our previous study (3). For example, compared with $\mathrm{CON}$ APD, FAIL APD was $72 \%$ longer in optically measured BDM-treated hearts, $102 \%$ longer in mechanically coupled hearts, and $111 \%$ longer in single myocytes. Thus, although $\mathrm{BDM}$ has been reported to alter ion channel and $\mathrm{Ca}^{2+}$-handling properties, we have no evidence that this has impacted on the interpretation of our data.

Although myofiber disarray was correlated with APD, we did not find a significant correlation between fiber disarray and APD dispersion or CV. While fiber angle can be measured across the whole ventricular wall by DT-MRI, our optical mapping of electrical activity was restricted to the epicardial surface. Technical developments allowing transmural mapping, such as endocardial and epicardial illumination and longer wavelength voltage-sensitive dyes (59), may in the future address this limitation.

There are reports of MCT-treated animals dying suddenly and of high mortality rates in some studies (e.g., Ref. 15). Although not proven, sudden deaths are likely to be associated with lethal arrhythmias. However, despite the presence of prominent $\mathrm{T}$-wave alternans in vivo, we only rarely observed extra systoles and did not observe severe arrhythmias. Our ethical permissions required intervention when animals began to display external signs of heart failure; we predict that these signs occur before the onset of end-stage heart failure and the development of lethal arrhythmias. This conclusion is consistent with a recent study by Umar et al. (56), who used a more severe end point than our own. They showed spontaneous fibrillation in isolated hearts from MCT-treated rats. Taken together, our present study and that of Umar et al. (56) indicate a progression from alternans to fibrillation in this model.

Conclusions and implications. We conclude that mechanisms including 1) steep electrical restitution and increased electrical heterogeneity, 2) myofiber disarray, and 3) dysfunction of $\mathrm{SR} \mathrm{Ca}^{2+}$ uptake and release lead to the generation of alternans and the proarrhythmic state in RV failure induced by pulmonary hypertension. These mechanisms have also been reported in left-sided heart failure, and this similarity between the ventricles supports the hypothesis that LV treatments, at present not used in the RV, may be appropriate for the hypertensive RV (19), where sudden death is a prominent feature and where therapeutic strategies to target the failing RV would be welcome (19). However, the observation that $\left[\mathrm{Ca}^{2+}\right]_{\mathrm{i}}$ transients remain elevated in RV failing myocytes, in contrast to most (5) but not all LV models (42), also indicates that direct extrapolation of LV findings to the RV should be made cautiously.

\section{GRANTS}

This work was supported by British Heart Foundation Grant PG/08/027/ 24774 (to E. White, M. J. Drinkhill, and D. A. Saint); Medical Research Council Grants G900524 (to E. White, O. Bernus, and A. P. Benson), G0701776 (to A. P. Benson), and G0701785 (to S. H. Gilbert); and an Emma and Leslie Reid endowed PhD studentship (to D. Benoist).

\section{DISCLOSURES}

No conflicts of interest, financial or otherwise, are declared by the author(s).

\section{AUTHOR CONTRIBUTIONS}

Author contributions: D.B., R.S., M.J.D., A.P.B., Z.Y., C.C., S.H.G. D.A.S., O.F.C., O.B., and E.W. performed experiments; D.B., R.S., M.J.D., A.P.B., Z.Y., C.C., S.H.G., D.S.S., O.B., and E.W. analyzed data; D.B., R.S., M.J.D., A.P.B., Z.Y., C.C., S.H.G., D.A.S., O.F.C., O.B., and E.W. interpreted results of experiments; D.B., R.S., A.P.B., Z.Y., C.C., S.H.G., D.S.S., O.B., and E.W. prepared figures; D.B. and E.W. drafted manuscript; D.B., R.S. M.J.D., A.P.B., Z.Y., C.C., S.H.G., D.A.S., O.F.C., D.S.S., O.B., and E.W edited and revised manuscript; D.B., R.S., M.J.D., A.P.B., Z.Y., C.C., S.H.G., D.A.S., O.F.C., D.S.S., O.B., and E.W. approved final version of manuscript; A.P.B., D.A.S., D.S.S., O.B., and E.W. conception and design of research.

\section{REFERENCES}

1. Antzelevitch C. Role of spatial dispersion of repolarization in inherited and acquired sudden cardiac death syndromes. Am J Physiol Heart Circ Physiol 293: H2024-H2038, 2007.

2. Antzelevitch C, Sicouri S, Di Diego JM, Burashnikov A, Viskin S, Shimizu W, Yan GX, Kowey P, Zhang L. Does Tpeak-Tend provide an index of transmural dispersion of repolarization? Heart Rhythm 4: 1114 1116, 2007.

3. Benoist D, Stones R, Drinkhill M, Bernus O, White E. Arrhythmogenic substrate in hearts of rats with monocrotaline-induced pulmonary hypertension and right ventricular hypertrophy. Am J Physiol Heart Circ Physiol 300: H2230-H2237, 2011.

4. Benson AP, Gilbert SH, Li P, Newton SM, Holden AV. Reconstruction and quantification of diffusion tensor imaging-derived cardiac fibre and sheet structure in ventricular regions used in studies of excitation propagation. Math Model Nat Phenom 3: 101-130, 2008.

5. Bers DM, Despa S, Bossuyt J. Regulation of $\mathrm{Ca}^{2+}$ and $\mathrm{Na}^{+}$in normal and failing cardiac myocytes. Ann NY Acad Sci 1080: 165-177, 2006.

6. Bogaard HJ, Abe K, Vonk NA, Voelkel NF. The right ventricle under pressure: cellular and molecular mechanisms of right-heart failure in pulmonary hypertension. Chest 135: 794-804, 2009.

7. Bovill JG. Intravenous anesthesia for the patient with left ventricular dysfunction. Semin Cardiothorac Vasc Anesth 10: 43-48, 2006.

8. Cheng H, Lederer WJ. Calcium sparks. Physiol Rev 88: 1491-1545, 2008.

9. Cutler MJ, Rosenbaum DS. Explaining the clinical manifestations of T wave alternans in patients at risk for sudden cardiac death. Heart Rhythm 6: S22-S28, 2009.

10. D'Alonzo GE, Barst RJ, Ayres SM, Bergofsky EH, Brundage BH, Detre KM, Fishman AP, Goldring RM, Groves BM, Kernis JT. Survival in patients with primary pulmonary hypertension. Results from a national prospective registry. Ann Intern Med 115: 343-349, 1991

11. de Simone G, Wallerson DC, Volpe M, Devereux RB. Echocardiographic measurement of left ventricular mass and volume in normotensive and hypertensive rats. Necropsy validation. Am J Hypertens 3: 688-696, 1990.

12. Diaz ME, Graham HK, Trafford AW. Enhanced sarcolemmal $\mathrm{Ca}^{2+}$ efflux reduces sarcoplasmic reticulum $\mathrm{Ca}^{2+}$ content and systolic $\mathrm{Ca}^{2+}$ in cardiac hypertrophy. Cardiovasc Res 62: 538-547, 2004.

13. Diaz ME, O'Neill SC, Eisner DA. Sarcoplasmic reticulum calcium content fluctuation is the key to cardiac alternans. Circ Res 94: 650-656, 2004.

14. Dibb KM, Eisner DA, Trafford AW. Regulation of systolic $\left[\mathrm{Ca}^{2+}\right]_{\mathrm{i}}$ and cellular $\mathrm{Ca}^{2+}$ flux balance in rat ventricular myocytes by SR Ca${ }^{2+}, \mathrm{L}$-type $\mathrm{Ca}^{2+}$ current and diastolic $\left[\mathrm{Ca}^{2+}\right]_{\mathrm{i}}$. J Physiol 585: 579-592, 2007. 
15. Endo H, Miura M, Hirose M, Takahashi J, Nakano M, Wakayama Y, Sugai Y, Kagaya Y, Watanabe J, Shirato K, Shimokawa H. Reduced inotropic effect of nifekalant in failing hearts in rats. J Pharmacol Exp Ther 318: 1102-1107, 2006.

16. Engelman ZJ, Trew ML, Smaill BH. Structural heterogeneity alone is a sufficient substrate for dynamic instability and altered restitution. Circ Arrhythm Electrophysiol 3: 195-203, 2010.

17. Folino AF, Bobbo F, Schiraldi C, Tona F, Romano S, Buja G, Bellotto F. Ventricular arrhythmias and autonomic profile in patients with primary pulmonary hypertension. Lung 181: 321-328, 2003.

18. Haddad F, Doyle R, Murphy DJ, Hunt SA. Right ventricular function in cardiovascular disease, part II: pathophysiology, clinical importance, and management of right ventricular failure. Circulation 117: 1717-1731, 2008.

19. Handoko ML, de Man FS, Allaart CP, Paulus WJ, Westerhof N, Vonk-Noordegraaf A. Perspectives on novel therapeutic strategies for right heart failure in pulmonary arterial hypertension: lessons from the left heart. Eur Respir Rev 19: 72-82, 2010.

20. Handoko ML, de Man FS, Happe CM, Schalij I, Musters RJ, Westerhof N, Postmus PE, Paulus WJ, van der Laarse WJ, Vonk-Noordegraaf A. Opposite effects of training in rats with stable and progressive pulmonary hypertension. Circulation 120: 42-49, 2009.

21. Hardziyenka M, Campian ME, de Bruin-Bon HA, Michel MC, Tan HL. Sequence of echocardiographic changes during development of right ventricular failure in rat. J Am Soc Echocardiogr 19: 1272-1279, 2006.

22. Henkens IR, Mouchaers KT, Vliegen HW, van der Laarse WJ, Swenne CA, Maan AC, Draisma HH, Schalij I, van der Wall EE, Schalij MJ, Vonk-Noordegraaf A. Early changes in rat hearts with developing pulmonary arterial hypertension can be detected with threedimensional electrocardiography. Am J Physiol Heart Circ Physiol 293: H1300-H1307, 2007.

23. Henkens IR, Mouchaers KT, Vonk-Noordegraaf A, Boonstra A, Swenne CA, Maan AC, Man SC, Twisk JW, van der Wall EE, Schalij MJ, Vliegen HW. Improved ECG detection of presence and severity of right ventricular pressure load validated with cardiac magnetic resonance imaging. Am J Physiol Heart Circ Physiol 294: H2150-H2157, 2008.

24. Hessel MH, Steendijk P, den Adel B, Schutte CI, van der Laarse A. Characterization of right ventricular function after monocrotaline-induced pulmonary hypertension in the intact rat. Am J Physiol Heart Circ Physiol 291: H2424-H2430, 2006

25. Hilliard FA, Steele DS, Laver D, Yang Z, Le Marchand SJ, Chopra N, Piston DW, Huke S, Knollmann BC. Flecainide inhibits arrhythmogenic $\mathrm{Ca}^{2+}$ waves by open state block of ryanodine receptor $\mathrm{Ca}^{2+}$ release channels and reduction of $\mathrm{Ca}^{2+}$ spark mass. J Mol Cell Cardiol 48: 293-301, 2010

26. Hlaing T, Guo D, Zhao X, DiMino T, Greenspon L, Kowey PR, Yan GX. The QT and Tp-e intervals in left and right chest leads: comparison between patients with systemic and pulmonary hypertension. $J$ Electrocardiol 38: 154-158, 2005.

27. Hong-liang Z, Qin L, Zhi-hong L, Zhi-hui Z, Chang-ming X, Xin-hai $\mathbf{N}$, Jian-guo $\mathbf{H}$, Ying-jie W, Shu $\mathbf{Z}$. Heart rate-corrected QT interval and QT dispersion in patients with pulmonary hypertension. Wien Klin Wochenschr 121: 330-333, 2009.

28. Houser SR, Margulies KB. Is depressed myocyte contractility centrally involved in heart failure? Circ Res 92: 350-358, 2003

29. Hyatt CJ, Zemlin CW, Smith RM, Matiukas A, Pertsov AM, Bernus O. Reconstructing subsurface electrical wave orientation from cardiac epi-fluorescence recordings: Monte Carlo versus diffusion approximation. Opt Express 16: 13758-13772, 2008.

30. Jones JE, Mendes L, Rudd MA, Russo G, Loscalzo J, Zhang YY. Serial noninvasive assessment of progressive pulmonary hypertension in a rat model. Am J Physiol Heart Circ Physiol 283: H364-H371, 2002.

31. Kawara T, Derksen R, de Groot JR, Coronel R, Tasseron S, Linnenbank AC, Hauer RN, Kirkels H, Janse MJ, de Bakker JM. Activation delay after premature stimulation in chronically diseased human myocardium relates to the architecture of interstitial fibrosis. Circulation 104: 3069-3075, 2001.

32. Keldermann RH, Ten Tusscher KH, Nash MP, Hren R, Taggart $\mathbf{P}$, Panfilov AV. Effect of heterogeneous APD restitution on VF organization in a model of the human ventricles. Am J Physiol Heart Circ Physiol 294: H764-H774, 2008

33. Kogler H, Hartmann O, Leineweber K, Nguyen vP, Schott P, Brodde OE, Hasenfuss G. Mechanical load-dependent regulation of gene expres- sion in monocrotaline-induced right ventricular hypertrophy in the rat. Circ Res 93: 230-237, 2003.

34. Kondo RP, Dederko DA, Teutsch C, Chrast J, Catalucci D, Chien KR, Giles WR. Comparison of contraction and calcium handling between right and left ventricular myocytes from adult mouse heart: a role for repolarization waveform. J Physiol 571: 131-146, 2006.

35. Laurita KR, Rosenbaum DS. Cellular mechanisms of arrhythmogenic cardiac alternans. Prog Biophys Mol Biol 97: 332-347, 2008.

36. Lee JK, Kodama I, Honjo H, Anno T, Kamiya K, Toyama J. Stagedependent changes in membrane currents in rats with monocrotalineinduced right ventricular hypertrophy. Am J Physiol Heart Circ Physiol 272: H2833-H2842, 1997.

37. Lee JK, Nishiyama A, Kambe F, Seo H, Takeuchi S, Kamiya K, Kodama I, Toyama J. Downregulation of voltage-gated $\mathrm{K}^{+}$channels in rat heart with right ventricular hypertrophy. Am J Physiol Heart Circ Physiol 277: H1725-H1731, 1999.

38. Li Y, Diaz ME, Eisner DA, O'Neill S. The effects of membrane potential, SR $\mathrm{Ca}^{2+}$ content and RyR responsiveness on systolic $\mathrm{Ca}^{2+}$ alternans in rat ventricular myocytes. J Physiol 587: 1283-1292, 2009.

39. Lou Q, Li W, Efimov IR. The role of dynamic instability and wavelength in arrhythmia maintenance as revealed by panoramic imaging with blebbistatin vs. 2,3-butanedione monoxime. Am J Physiol Heart Circ Physiol 302: H262-H269, 2012

40. McCrossan ZA, Billeter R, White E. Transmural changes in size contractile and electrical properties of SHR left ventricular myocytes during compensated hypertrophy. Cardiovasc Res 63: 283-292, 2004.

41. Meyer BL, Bogart DB, Carley JE, Wong BY, Dunn MI. Pulmonary arterial pulsus alternans secondary to primary pulmonary hypertension. Chest 70: 374-377, 1976

42. Mork HK, Sjaastad I, Sande JB, Periasamy M, Sejersted OM, Louch WE. Increased cardiomyocyte function and $\mathrm{Ca}^{2+}$ transients in mice during early congestive heart failure. J Mol Cell Cardiol 43: 177-186, 2007.

43. Myles RC, Burton FL, Cobbe SM, Smith GL. Alternans of action potential duration and amplitude in rabbits with left ventricular dysfunction following myocardial infarction. J Mol Cell Cardiol 50: 510-521, 2011.

44. Opthof T, Coronel R, Wilms-Schopman FJ, Plotnikov AN, Shlapakova IN, Danilo P Jr, Rosen MR, Janse MJ. Dispersion of repolarization in canine ventricle and the electrocardiographic T wave: Tp-e interval does not reflect transmural dispersion. Heart Rhythm 4: 341-348, 2007.

45. Papadakis NG, Xing D, Huang CL, Hall LD, Carpenter TA. A comparative study of acquisition schemes for diffusion tensor imaging using MRI. J Magn Reson 137: 67-82, 1999.

46. Piacentino V, III, Weber CR, Chen X, Weisser-Thomas J, Margulies KB, Bers DM, Houser SR. Cellular basis of abnormal calcium transients of failing human ventricular myocytes. Circ Res 92: 651-658, 2003.

47. Piao L, Fang YH, Cadete VJ, Wietholt C, Urboniene D, Toth PT, Marsboom G, Zhang HJ, Haber I, Rehman J, Lopaschuk GD, Archer SL. The inhibition of pyruvate dehydrogenase kinase improves impaired cardiac function and electrical remodeling in two models of right ventricular hypertrophy: resuscitating the hibernating right ventricle. $\mathrm{J} \mathrm{Mol} \mathrm{Med}$ 88: 47-60, 2010.

48. Picht E, DeSantiago J, Blatter LA, Bers DM. Cardiac alternans do not rely on diastolic sarcoplasmic reticulum calcium content fluctuations. Circ Res 99: 740-748, 2006

49. Qu Z, Xie Y, Garfinkel A, Weiss JN. T-wave alternans and arrhythmogenesis in cardiac diseases. Front Physiol 1: 154, 2010.

50. Sahn DJ, DeMaria A, Kisslo J, Weyman A. Recommendations regarding quantitation in M-mode echocardiography: results of a survey of echocardiographic measurements. Circulation 58: 1072-1083, 1978.

51. Sanyal SN, Ono K. Derangement of autonomic nerve control in rat with right ventricular failure. Pathophysiology 8: 197-203, 2002.

52. Scollan DF, Holmes A, Winslow R, Forder J. Histological validation of myocardial microstructure obtained from diffusion tensor magnetic resonance imaging. Am J Physiol Heart Circ Physiol 275: H2308-H2318, 1998.

53. Selvaraj RJ, Picton P, Nanthakumar K, Chauhan VS. Steeper restitution slopes across right ventricular endocardium in patients with cardiomyopathy at high risk of ventricular arrhythmias. Am J Physiol Heart Circ Physiol 292: H1262-H1268, 2007.

54. Slama M, Susic D, Varagic J, Ahn J, Frohlich ED. Echocardiographic measurement of cardiac output in rats. Am J Physiol Heart Circ Physiol 284: H691-H697, 2003. 
55. Takebayashi S, Li Y, Kaku T, Inagaki S, Hashimoto Y, Kimura K, Miyamoto S, Hadama T, Ono K. Remodeling excitation-contraction coupling of hypertrophied ventricular myocytes is dependent on T-type calcium channels expression. Biochem Biophys Res Commun 345: 766773, 2006

56. Umar S, Lee JH, de LE, Iorga A, Partow-Navid R, Bapat A, van der LA, Saggar R, Saggar R, Ypey DL, Karagueuzian HS, Eghbali M. Spontaneous ventricular fibrillation in right ventricular failure secondary to chronic pulmonary hypertension. Circ Arrhythm Electrophysiol 5: 181-190, 2012

57. Uzzaman M, Honjo H, Takagishi Y, Emdad L, Magee AI, Severs NJ, Kodama I. Remodeling of gap junctional coupling in hypertrophied right ventricles of rats with monocrotaline-induced pulmonary hypertension. Circ Res 86: 871-878, 2000.

58. Voelkel NF, Quaife RA, Leinwand LA, Barst RJ, McGoon MD, Meldrum DR, Dupuis J, Long CS, Rubin LJ, Smart FW, Suzuki YJ, Gladwin M, Denholm EM, Gail DB. Right ventricular function and failure: report of a National Heart, Lung, and Blood Institute working group on cellular and molecular mechanisms of right heart failure. Circulation 114: 1883-1891, 2006.

59. Walton RD, Benoist D, Hyatt CJ, Gilbert SH, White E, Bernus O. Dual excitation wavelength epifluorescence imaging of transmural electrophysiological properties in intact hearts. Heart Rhythm 7: 1843-1849, 2010.
60. Weiss JN, Nivala M, Garfinkel A, Qu Z. Alternans and arrhythmias: from cell to heart. Circ Res 108: 98-112, 2011.

61. Yang Z, Ikemoto N, Lamb GD, Steele DS. The RyR2 central domain peptide DPc10 lowers the threshold for spontaneous $\mathrm{Ca}^{2+}$ release in permeabilized cardiomyocytes. Cardiovasc Res 70: 475-485, 2006.

62. Yang Z, Steele DS. Effects of cytosolic ATP on $\mathrm{Ca}^{2+}$ sparks and $\mathrm{SR} \mathrm{Ca}^{2+}$ content in permeabilized cardiac myocytes. Circ Res 89: 526-533, 2001.

63. Zipes DP, Camm AJ, Borggrefe M, Buxton AE, Chaitman B, Fromer M, Gregoratos G, Klein G, Moss AJ, Myerburg RJ, Priori SG, Quinones MA, Roden DM, Silka MJ, Tracy C, Smith SC Jr, Jacobs AK, Adams CD, Antman EM, Anderson JL, Hunt SA, Halperin JL, Nishimura R, Ornato JP, Page RL, Riegel B, Blanc JJ, Budaj A, Dean V, Deckers JW, Despres C, Dickstein K, Lekakis J, McGregor K, Metra M, Morais J, Osterspey A, Tamargo JL, Zamorano JL. ACC/ AHA/ESC 2006 Guidelines for Management of Patients With Ventricular Arrhythmias and the Prevention of Sudden Cardiac Death: a report of the American College of Cardiology/American Heart Association Task Force and the European Society of Cardiology Committee for Practice Guidelines (writing committee to develop Guidelines for Management of $\mathrm{Pa}$ tients With Ventricular Arrhythmias and the Prevention of Sudden Cardiac Death): developed in collaboration with the European Heart Rhythm Association and the Heart Rhythm Society. Circulation 114: e385-e484, 2006. 